\title{
La evolución tecnológica del distrito cerámico de Castellón: la contribución de la industria de fritas, colores y esmaltes
}

\author{
E. TORTAJADA ESPARZA*, D. GABALDÓN ESTEVAN*, I. FERNÁNDEZ DE LUCIO* \\ *Instituto de Gestión de la Innovación y del Conocimiento - INGENIO (CSIC - UPV)
}

\begin{abstract}
El distrito industrial de Castellón se caracteriza por un gran dinamismo fundamentado en la innovación tecnológica, tanto de proceso como de producto, cuyo origen está básicamente en sus proveedores (1), la industria de equipamiento mecánico y la industria de fritas, esmaltes y colores cerámicos. En este artículo se analiza la situación actual de la industria de fritas, esmaltes y colores cerámicos española, atendiendo además a la situación de su mayor competidor europeo, Italia. Se describe también la formación y desarrollo de la industria en el entorno del distrito cerámico de Castellón y de su sistema de innovación, se analizan, asimismo la actividad en I+D e innovación así como los hitos tecnológicos que le han llevado a ocupar un liderazgo mundial. El análisis realizado identifica los retos frente a los que el subsector y, en general, el sistema de innovación cerámico necesitan reaccionar, cooperando, con el fin de mantener el liderazgo del distrito cerámico. La globalización implica nuevos comportamientos y uno de los más importantes es el aumento de la cooperación entre los actores del sistema de innovación.
\end{abstract}

Palabras clave: cerámica, esmaltes, innovación tecnológica, distrito industrial, sistema de innovación.

The technological evolution of the Castellón ceramic tile district: the contribution of the frit, glaze and colour industry

The industrial district of Castellon is characterized by a great dynamism based on technological innovation, both product and process, the origins of which are to be found on its providers (1), the machinery industry and the frit, glaze and colours industry. In this paper the current situation of the frit, glaze and colour industry is analyzed, accounting also for the situation of its main European competitor in Italy. The formation and development of the industry is also described in relation to the industrial district and the innovation system where it belongs, together with the R\&D activity, the innovation activity, and the main technological milestones that have made it become the world leader. The analysis shows the challenges to which this subsector, and more generally, the tile innovation system need to react to, by means of cooperation, in order to maintain the tile district leadership. Globalization implies new behaviours and one of the most relevant is the increase of cooperation among the different actors in the innovation system. .

Key words: ceramic tiles, glazes, technological innovation, industrial district, innovation system.

\section{INTRODUCCIÓN}

El sector cerámico español ha crecido en las últimas décadas apoyándose en la expansión del sector de la construcción, y dando respuesta a una demanda crecientemente sofisticada de baldosas para el revestimiento de paredes y suelos. La actividad, históricamente dispersa, se concentra en puntos, como Castellón en España y Sassuolo en Italia, dando lugar a sendos distritos industriales, en el sentido descrito por Marshall (2).

El distrito de Castellón se caracteriza por un gran dinamismo fundamentado en la innovación tecnológica, cuyo origen está básicamente en los proveedores (1) que son, por un lado, la industria de equipamiento mecánico -extranjera, esencialmente, italiana-, que suministra prensas, hornos y equipos diversos; y, por otro lado, la industria de fritas, esmaltes y colores cerámicos, proveedora de los materiales constituyentes del esmalte, que proporciona a las baldosas unas cualidades físicas y estéticas muy valoradas.

Este subsector de la industria química, íntimamente ligado al colectivo cerámico, es joven en España, habiéndose separado progresivamente del subsector cerámico desde hace de unos cincuenta años. Además de proveer de materias primas del esmaltado, viene a proporcionar unos servicios y unas soluciones tecnológicas, que han influido en la evolución y el dinamismo del producto cerámico y por ende de la industria cerámica. Esta aseveración es compartida por muchos autores y por los agentes del distrito cerámico $(3,4,5)$.

$\mathrm{Al}$ igual que su industria cliente, es netamente exportadora y ha abierto delegaciones comerciales y plantas de producción en mercados externos allí donde existe y se desarrolla la industria cerámica (6).

Este subsector se ha convertido en fundamental para el cerámico, generando y transfiriendo tecnología e integrándose 
en su entorno tecnológico (7). Pareciera como si el desarrollo de la industria fabricante de pavimentos y revestimientos, bien estudiado en la literatura técnica $(3,8,9,10)$, hubiese ocultado el papel clave desempeñado por la industria del esmalte. En general, se ha destacado más el papel de la industria mecánica suministradora de mejoras tecnológicas en el proceso de producción cerámico, que le ha permitido reducir el coste energético por unidad de producto, aunque también se ha expresado la importancia del esfuerzo en innovación asumido por este grupo de empresas y por instituciones del entorno científico y tecnológico, especialmente el efectuado a través de las relaciones establecidas con algunos departamentos de la Universidad Jaime I (UJI), el Instituto de Tecnología Cerámica (ITC) y el Instituto de Cerámica y Vidrio del Consejo Superior de Investigaciones Científicas (CSIC), (11).

El subsector está afrontando en los últimos años unos retos importantes a los que ha de dar respuesta eficaz. Por un lado, acusa un incremento de sus gastos (es una gran consumidora de energía y de ciertas materia primas, como el óxido de zinc, zirconio y pigmentos cuyos precios se han elevando mucho), mientras que los precios de sus productos no han mejorado en términos reales por la presión competitiva de los nuevos países productores, por lo que afronta una persistente reducción de rentabilidad $(11,12,13)$. Además, se le aplica una legislación ambiental cada vez más rigurosa a causa de la creciente demanda social de pautas de producción y consumo más sostenibles, derivadas de compromisos internacionales (Directiva IPPT, programa REACH, Protocolo de Kyoto, etc.), que puede tener impacto sobre su competitividad por la carga administrativa que impondrán y por los costes de implantación y de mantenimiento de las instalaciones afectadas $(11,14)$.

El subsector de fritas y esmaltes, compuesto por 27 empresas, factura actualmente cerca de mil millones de euros anuales (1033 en el año 2006, y 1100 en 2007), y emplea cerca de cuatro mil trabajadores (3776). Está compuesto pues, por empresas grandes, que contrasta con la estructura industrial predominante en la Comunidad Valenciana, y están ubicadas la mayoría en las comarcas L'Alcalaten y la Plana de Castellón, ambas incluidas en el distrito cerámico de Castellón.

A pesar de la importancia que se deriva de esto datos, el grado de conocimiento que se tiene sobre esta industria no es elevado ni suficiente, ni en la sociedad en general, ni dentro del distrito cerámico en particular. Por ello, en el presente trabajo se pretende analizar la formación de esta industria y su evolución temporal, aportando ideas clave sobre su desarrollo, poco conocidas o ignoradas hasta el presente. En especial, se intenta clarificar su papel en la evolución y consolidación del distrito cerámico de Castellón. A estos efectos, se ha efectuado un análisis bibliográfico sobre el subsector y sus relaciones con la cerámica, y se ha obtenido información de las bases de datos que proporcionan información estadística empresarial (fundamentalmente, SABI) y las fuentes oficiales (INE, ICEX, Comercio Exterior, etc.). Esta información se ha contrastado mediante entrevistas semiestructuradas a personas conocedoras de la problemática innovadora y empresarial del subsector.

El trabajo se estructura en torno a seis apartados. Tras la introducción, el apartado 2 viene a delimitar el subsector, enmarcándolo en su contexto. En el 3, se analiza el estado actual de esta industria estableciendo comparaciones con la industria italiana. En el apartado 4 se analiza la formación histórica del subsector y los hitos habidos en su evolución junto con el subsector cerámico. El apartado 5 se dedica a estudiar el papel de la industria de esmaltes en el sistema sectorial de innovación cerámico y su aportación al progreso tecnológico del mismo. Finalmente, el apartado 6 contiene las conclusiones más relevantes.

\section{DELIMITACIÓN DE LA INDUSTRIA DE FRITAS, ESMALTES Y COLORES CERÁMICOS}

Esta industria aporta a la fabricación cerámica los materiales que, tras un proceso de cocción en horno (donde se produce el esmaltado), generarán sobre la base arcillosa de la cerámica una capa o recubrimiento superficial (esmalte) que dotará al producto de unas características o cualidades físicas y estéticas deseables que antes no tenía. Estos materiales son: fritas, esmaltes, colores, y otros coadyuvantes al proceso (engobes, lustres y aditivos en general).

La Fig. 1 representa de forma esquemática a los productos y a los flujos de estos materiales. Se observa el posicionamiento del subsector en el contexto de industria la cerámica en relación al resto de agentes que intervienen. La mayoría de las materias primas que intervienen en los esmaltes son minerales naturales (arcillas, caolín, feldespatos, arenas diversas, boratos, etc.) que, tras su extracción, sufren diferentes tratamientos para adecuarlos a las propiedades químicas y físicas específicas que requiere la industria del esmalte. Los tratamientos que efectúan los distintos agentes extractores, acondicionadores de minerales, atomizadoras y distribuidores mayoristas en general, deben ofrecer unos materiales acondicionados y homogeneizados en cuanto a pureza y composición química, granulometría, etc. Otro sector clave para esta industria lo constituyen los fabricantes de pigmentos y colorantes inorgánicos, productos químicos de síntesis en su casi totalidad, así como a los fabricantes de aditivos (en este caso, normalmente de tipo orgánico: fluidizantes, vehículos diversos, etc.) empleados en el esmaltado. Todos ellos surten directamente a los fabricantes de cerámica o bien a los de fritas. Detalles estos productos y el proceso productivo pueden encontrarse en numerosas referencias, por ejemplo (15).

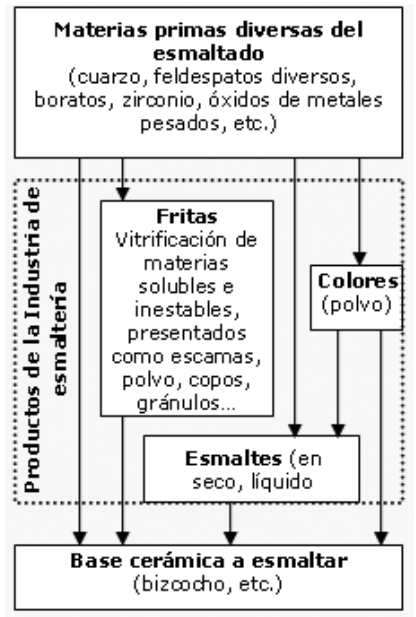

Fig. 1- Productos de la industria de esmaltes. Fuente: Elaboración propia.

Cabe indicar que la fabricación de los productos centrales de la industria del esmalte corresponde a actividades con el código CNAE 2430 (distinto, pues del código CNAE 2630 habitual de los ceramistas), englobada con la fabricación de pinturas y otros revestimientos. 
TABLA I. INDUSTRIA DE FRITAS, ESMALTES Y COLORES CERÁMICOS. ESPAÑA. 2005

\begin{tabular}{|c|c|c|c|c|c|c|}
\hline & \multirow{2}{*}{ EMPRESA } & \multirow{2}{*}{ LOCALIDAD } & \multirow{2}{*}{$\begin{array}{c}\begin{array}{c}\text { FACTU- } \\
\text { RACIÓN }\end{array} \\
\begin{array}{c}\text { Miles de } \\
\text { euros }\end{array}\end{array}$} & \multicolumn{3}{|c|}{ EMPLEADOS } \\
\hline & & & & $\mathbf{N}^{\circ}$ & $(\%)$ & $\begin{array}{l}(\%) \\
\text { Acum. }\end{array}$ \\
\hline 1 & $\begin{array}{l}\text { FERRO SPAIN S.A. } \\
\text { (a) }\end{array}$ & Almazora & 174.566 & 734 & $18 \%$ & $18 \%$ \\
\hline 2 & $\begin{array}{l}\text { COLOROBBIA } \\
\text { ESPANA S.A. }\end{array}$ & Vilafames & 120.738 & 387 & $10 \%$ & $28 \%$ \\
\hline 3 & ESMALGLASS S.A. & Villarreal & 108.139 & 400 & $10 \%$ & $38 \%$ \\
\hline 4 & TORRECID S.A. & Alcora & 87.961 & 330 & $8 \%$ & $46 \%$ \\
\hline 5 & $\begin{array}{l}\text { ITACA. INNOV. } \\
\text { TECN. APLIC. CER. } \\
\text { AVANZ. S.A. }\end{array}$ & $\begin{array}{l}\text { Pobla } \\
\text { Tornesa }\end{array}$ & 71.899 & 217 & $5 \%$ & $51 \%$ \\
\hline 6 & \begin{tabular}{|l|} 
JOHNSON \\
MATTHEY \\
CERAMICS S.A. (b) \\
\end{tabular} & $\begin{array}{l}\text { Castellón de } \\
\text { la Plana }\end{array}$ & 61.259 & 183 & $5 \%$ & $56 \%$ \\
\hline 7 & FRITTA S.L. & Onda & 45.731 & 199 & $5 \%$ & $61 \%$ \\
\hline 8 & QUIMICER S.A. & Onda & 34.066 & 153 & $4 \%$ & $64 \%$ \\
\hline 9 & \begin{tabular}{|l|} 
COLORIFICIO \\
CERAMICO BONET \\
S.A. \\
\end{tabular} & Ribesalves & 33.774 & 153 & $4 \%$ & $68 \%$ \\
\hline 10 & $\begin{array}{l}\text { SALQUISA. SAN } \\
\text { ALF QUIMICAS } \\
\text { S.A. (a) }\end{array}$ & Cabanes & 31.845 & 112 & $3 \%$ & $71 \%$ \\
\hline 11 & ESMALTES S.A. & Alcora & 29.232 & 117 & $3 \%$ & $74 \%$ \\
\hline 12 & $\begin{array}{l}\text { COLORES CERAM. } \\
\text { DE TORTOSA S.A. }\end{array}$ & Tortosa & 24.159 & 142 & $4 \%$ & $77 \%$ \\
\hline 13 & COLORONDA S.L. & Onda & 23.160 & 83 & $2 \%$ & $79 \%$ \\
\hline 14 & VIDRES S.A. & Villarreal & 23.684 & 125 & $3 \%$ & $83 \%$ \\
\hline 15 & AL FARBEN S.A. & Alcora & 22.158 & 89 & $2 \%$ & $85 \%$ \\
\hline 16 & CERFRIT S.A. & Nules & 19.534 & 146 & $4 \%$ & $88 \%$ \\
\hline 17 & VERNIS S.A. & Onda & 15.897 & 70 & $2 \%$ & $90 \%$ \\
\hline 18 & $\begin{array}{l}\text { EUROARCE COLOR } \\
\text { ESMALT S.A. }\end{array}$ & Alcora & 14.610 & 87 & $2 \%$ & $92 \%$ \\
\hline 19 & $\begin{array}{l}\text { PEMCO ESMALTES } \\
\text { S.L. }\end{array}$ & Vitoria & 10.597 & 74 & $2 \%$ & $94 \%$ \\
\hline 20 & $\begin{array}{l}\text { WENDEL EMAIL } \\
\text { IBERICA S.A. (c) }\end{array}$ & Nules & 10.370 & 53 & $1 \%$ & $95 \%$ \\
\hline 21 & ESMALDUR S.A. & $\begin{array}{l}\text { San Joan } \\
\text { Moro }\end{array}$ & 9.894 & 37 & $1 \%$ & $96 \%$ \\
\hline 22 & $\begin{array}{l}\text { COLORES } \\
\text { CERAMICOS S.A. }\end{array}$ & Onda & 9.648 & 51 & $1 \%$ & $98 \%$ \\
\hline 23 & $\begin{array}{l}\text { PRODESCO. } \\
\text { PRODUCT. ESMALT. } \\
\text { Y COL. S.L. }\end{array}$ & Manises & 4.344 & 41 & $1 \%$ & $99 \%$ \\
\hline 24 & VITRICOL S.A. (d) & Onda & 3.468 & 30 & $1 \%$ & $99 \%$ \\
\hline 25 & $\begin{array}{l}\text { COLORES OLUCHA } \\
\text { S.L. }\end{array}$ & Onda & 1.261 & 9 & $0 \%$ & $100 \%$ \\
\hline 26 & $\begin{array}{l}\text { COLORES } \\
\text { CERAMICOS } \\
\text { ELCOM, S.L. }\end{array}$ & Manises & 746 & 4 & $0 \%$ & $100 \%$ \\
\hline 27 & $\begin{array}{l}\text { COLOR. } \\
\text { CERAMICOS } \\
\text { LAHUERTA S.L. }\end{array}$ & Manises & 586 & 11 & $0 \%$ & $100 \%$ \\
\hline & SUMA & $\ldots$ & 993.326 & 4.037 & $100 \%$ & \\
\hline
\end{tabular}

Notas: a) Ferro y Salquisa venden productos al margen del subsector que inciden significativamente en la facturación y en el ranking (colores orgánicos -Ferrofertilizantes y agroquímicos -Salquisa-, entre otros. B) Recientemente adquirida por ENDEKA CERAMICS Group. 2007; c) En la actualidad denominada KERAFRIT; d) Datos de 2003.

Fuente: Elaboración propia. SABI.

\subsection{Empresas constituyentes de la industria. Grupos.}

Se han identificado 27 empresas que producen y venden fritas, colores y esmaltes. En la Tabla I, se incluyen las empresas con actividad contrastada, ordenadas por la cifra de facturación La industria se localiza fundamentalmente en las comarcas centrales de Castellón (La Plana y L’Alcalatén). Onda, Alcora, Castellón, Villarreal, Almazora, Vilafamés, entre otras localidades, concentran más del $90 \%$ de la producción, en un área de $400 \mathrm{Km} 2$ con distancias entre sí no superiores a $25 \mathrm{Km}$. Fuera de este distrito figuran tres empresas en Valencia, concretamente en el área de Manises, otra en Vitoria (Álava) y una más en Tortosa (Tarragona).

El tamaño medio industrial es bastante elevado (148 empleados - 35 millones de facturación por empresa), contrastando con el predominio de las pequeñas empresas en amplios sectores de actividad en la Comunidad Valenciana. Existe un amplio abanico de empresas con dimensión dispersa, que van desde las de baja facturación, -no llegan al millón $€$ al año, muy especializadas-, hasta los grandes grupos con una facturación cercana o superior a 500 millones $€$, con producción muy diversificada y servicios de valor añadido, con plantas de producción y delegaciones en el exterior. El subsector posee una estructura concentrada, según se desprende de la información aportada en la Tabla II. Las 12 empresas de 100 o más empleados, el 44,4\% del total, agrupan al $80 \%$ de los trabajadores de la industria. Esta estructura se ha mantenido estable en los últimos años.

Se observa la presencia de varios grupos de empresas. En cuanto a los grupos de capital extranjero destacan: 1) Ferro Corporation: de origen norteamericano, dedicado al recubrimiento de metales que vio la oportunidad de acceder al mercado de los recubrimientos cerámicos; en su incorporación a los mercados español e italiano (Ferro Spain y Ferro Italia) procedió a través de la adquisición de varias empresas establecidas. 2) Grupo Colorobbia: Con origen en la Toscana (Italia); es uno de los grupos pioneros procedente de la emancipación de la sección de esmaltes de una empresa cerámica. 3) Otros grupos de capital extranjero de dimensión inferior son Johnson Matthey Ceramics y Pemco Internacional.

En cuanto a los nacionales cabe mencionar: 1) Grupo Torrecid: Procede del sector ceramista de Alcora; fundó Al Farben (colores) y ha adquirido recientemente el grupo Reimbold \& Strick que incluye a la compañía española Colores Cerámicos (Tortosa). 2) Grupo Esmalglass-Itaca, surgido a iniciativa de técnicos y empresarios ceramistas.

\section{PANORAMA NACIONAL E INTERNACIONAL}

\subsection{Evolución y destino de la producción}

Desde 1990 se produjo un crecimiento espectacular de la industria esmaltera llegando la facturación en 2006 a niveles próximos a mil millones de euros. Se contemplan dos fases en esta reciente evolución. En la primera, desde principios de los años 90 hasta el año 2002, hubo crecimientos lineales en las ventas, con aumentos anuales entre 55-60 millones $€$, correspondiendo un tercio al mercado interior y dos tercios a las exportaciones. Entre 2002 y 2005, esta pauta desaparece para el conjunto, pero no para la exportación, que sigue aumentando en $35-40$ millones $€$ anuales, mientras que las 
TABLA II. ESTRUCTURA INDUSTRIAL SEGÚN TAMAÑOS EMPRESARIALES. 2005

\begin{tabular}{|c|c|c|c|c|}
\hline & \multirow{3}{*}{ TOTAL } & \multicolumn{3}{|c|}{ EMPRESAS SEGÚN NÚMERO DE EMPLEADOS } \\
\hline & & MENOS DE 100 & ENTRE 100 Y 250 & MÁS DE 250 \\
\hline & & \multicolumn{2}{|c|}{ (pymes) } & (grandes empresas) \\
\hline EMPRESAS $\left(\mathrm{N}^{\circ}\right)$ & 27 & 13 & 10 & 4 \\
\hline EMPLEADOS $\left(\mathrm{n}^{\circ}\right.$ total $)$ & 4037 & 639 & 1.547 & 1.851 \\
\hline (empleados/empresa) & 150 & 49 & 155 & 463 \\
\hline \multicolumn{5}{|l|}{ FACTURACIÓN (Mill. €) } \\
\hline total & 993 & 127 & 375 & 491 \\
\hline por empresa & 37 & 10 & 38 & 123 \\
\hline por empleado & 0,25 & 0,2 & 0,24 & 0,27 \\
\hline INTEGRANTES & & $\begin{array}{l}\text { Coloronda, Al Farben, } \\
\text { Color Esmalt, Vernis, } \\
\text { Colores Cerámicos, } \\
\text { Pemco, Esmaldur, } \\
\text { Kerafrit, Prodesco, } \\
\text { Vitricol, C.Olucha, } \\
\text { C.C.Elcom, C.C,Lahuerta, }\end{array}$ & $\begin{array}{l}\text { Johson Matthey, ITACA, } \\
\text { Quimicer, Fritta, } \\
\text { C.C.Bonet, CC de Tortosa, } \\
\text { Salquisa, Vidres, Cerfrit, } \\
\text { Esmaltes }\end{array}$ & Ferro Spain, Colorobbia España, Esmalglass, Torrecid. \\
\hline
\end{tabular}

Fuente: Elaboración propia. SABI.

ventas nacionales se estancan o se reducen, al igual que lo hace la producción cerámica nacional. A partir de 2006 se produce un relanzamiento de las ventas en ambos destinos, si bien es pronto para confirmar un cambio sostenido de dicha tendencia.

La Tabla III aporta la evolución comparativa de la facturación y del empleo en el sector, así como de la ratio de productividad (ventas por empleado). El empleo sectorial ha crecido con regularidad hasta 2005; en catorce años se ha multiplicado por 2,5 hasta alcanzar los 3.800 trabajadores, según ANFFECC. En cuanto a la evolución de la facturación por trabajador cabe distinguir dos tramos, el primero, hasta 1997, con crecimiento desde $170.000 €$ hasta $240.000 € /$ empleado, ratio que se mantiene desde 1997 hasta el 2005, lo que implica una reducción en términos reales teniendo en cuenta la incidencia de la inflación. Las empresas españolas son grandes proveedoras tanto de la industria cerámica nacional

TABLA III. EVOLUCIÓN DE LA FACTURACIÓN Y DEL EMPLEO. 1992-2006

\begin{tabular}{|c|c|c|c|c|c|}
\hline \multirow{2}{*}{ Año } & \multicolumn{3}{|c|}{ Ventas (mill $€$ ) } & Trabajadores & Ventas/Trab. \\
\cline { 2 - 6 } & Exportación & $\begin{array}{c}\text { Ventas } \\
\text { España }\end{array}$ & Total & $\mathrm{N}^{\mathrm{o}}$ & (miles $€ /$ trab) \\
\hline 1992 & 91 & 157 & 248 & 1482 & 167 \\
\hline 1993 & 115 & 164 & 279 & 1650 & 169 \\
\hline 1994 & 160 & 197 & 357 & 1745 & 205 \\
\hline 1995 & 192 & 243 & 435 & 2049 & 212 \\
\hline 1996 & 227 & 252 & 479 & 2160 & 222 \\
\hline 1997 & 272 & 284 & 556 & 2321 & 240 \\
\hline 1998 & 294 & 326 & 621 & 2685 & 231 \\
\hline 1999 & 325 & 342 & 667 & 2737 & 244 \\
\hline 2000 & 377 & 350 & 726 & 3005 & 242 \\
\hline 2001 & 406 & 384 & 789 & 3319 & 238 \\
\hline 2002 & 458 & 378 & 836 & 3487 & 240 \\
\hline 2003 & 485 & 353 & 838 & 3626 & 231 \\
\hline 2004 & 535 & 353 & 889 & 3669 & 242 \\
\hline 2005 & 532 & 379 & 912 & 3818 & 239 \\
\hline 2006 & 603 & 431 & 1033 & 3776 & 274 \\
\hline
\end{tabular}

Fuente: ANFFECC. Elaboración propia como de la de otros países. Así la importación representa solo una séptima parte de las exportaciones y una sexta parte del consumo interior. En consecuencia la Tasa de Cobertura de las importaciones fue del 693\% en 2005.

Se puede decir, generalizando, que la industria de fritas, colores y esmaltes española, como proveedora de los fabricantes de cerámica, ha evolucionado lógicamente en paralelo con ésta última, y más concretamente de la producción de cerámica esmaltada, que supone el $94 \%$ de la producción total (16). Este no es el caso de la cerámica italiana, en que el peso del porcelánico técnico (no esmaltado) es mucho mayor.

\subsection{Composición de las importaciones y exportaciones.}

La balanza comercial para los productos de fritas, colores y esmaltes viene reflejando un amplio superávit. Las exportaciones españolas se distribuyen por todos los continentes, allá en donde se localice la industria cerámica, como indica la información recogida en la Tabla IV. En 2005, la mayor parte de las exportaciones $(41 \%)$ se dirigieron a Europa, mientras que el resto se distribuyó por África (21\%), Asia $(27 \%)$ y América $(10 \%)$.

Se orientan esencialmente hacia una serie de países que son abastecidos con regularidad en la última década. Por orden de importancia: Italia, Egipto, Portugal, Polonia, Indonesia, etc.

TABLA IV. EVOLUCIÓN DE LAS EXPORTACIONES DE FRITAS, ESMALTES Y COLORES CERÁMICOS. DESTINO GEOGRÁFICO DE LAS MISMAS. PERIODO 2000-2005.

\begin{tabular}{|l|c|c|c|c|c|c|}
\hline ZONA & 2000 & 2001 & 2002 & 2003 & 2004 & 2005 \\
\hline Europa & $38 \%$ & $40 \%$ & $38 \%$ & $39 \%$ & $40 \%$ & $41 \%$ \\
\hline África & $18 \%$ & $18 \%$ & $18 \%$ & $19 \%$ & $21 \%$ & $21 \%$ \\
\hline América & $12 \%$ & $11 \%$ & $11 \%$ & $11 \%$ & $10 \%$ & $10 \%$ \\
\hline Asia & $32 \%$ & $32 \%$ & $33 \%$ & $30 \%$ & $29 \%$ & $27 \%$ \\
\hline TOTAL & $100 \%$ & $100 \%$ & $100 \%$ & $100 \%$ & $100 \%$ & $100 \%$ \\
\hline Mill $€$ & 383 & 422 & 465 & 483 & 517 & 513 \\
\hline
\end{tabular}

Fuente: AEAT. Base de Datos de Comercio Exterior. Cámaras de Comercio. 
Ninguno de ellos recoge más del 12\% del total, lo que indica una gran dispersión de las ventas por países. En la Tabla V se exponen las cifras correspondientes a los cinco principales países importadores. Obsérvese que lo exportado a estos cinco países representa sólo un tercio del total exportado por la industria española de esmaltes. Se ha notado la reducción de importaciones desde principios del presente siglo en países más alejados, como Indonesia, Malasia y también en EEUU. Por el contrario, han crecido las exportaciones hacia Oriente Próximo, por ejemplo, Egipto y Unión de Emiratos Árabes.

Con respecto a las importaciones, es crónica su escasa dimensión relativa frente a las exportaciones, debido al fuerte peso de la industria española. En 2005 las importaciones de el precio medio de la exportación aumentó un 5\%, en realidad ha ocurrido que, al variar la ponderación de los componentes, favoreciendo a los productos más caros, el resultado medio es mayor. Individualmente, todos los precios se han reducido a excepción de los esmaltes, cuyo precio ha aumentado ligeramente $(+2 \%)$. Así, el valor medio de los demás productos ha descendido: la frita, un $4 \%$; los colores, un $7 \%$; y los lustres un $20 \%$. Con las ponderaciones iniciales, en peso, el precio medio ha descendido un $4 \%$. En contraste, la evolución de los precios de las materias primas ha sido adversa para la industria. Recientemente, materias como el óxido de cinc y el Zirconio, se han visto envueltos en espirales de precios ascendentes. En cuanto a los precios de exportación, para

TABLA V. DESTINO DE LAS EXPORTACIONES DE FRITAS, ESMALTES Y COLORES CERÁMICOS. PRINCIPALES PAÍSES RECEPTORES. AÑOS 2001-2004.

\begin{tabular}{|c|c|c|c|c|c|c|c|c|c|c|}
\hline \multirow{2}{*}{ País } & \multicolumn{2}{|c|}{2001} & \multicolumn{2}{|c|}{2002} & \multicolumn{2}{|c|}{2003} & \multicolumn{2}{|c|}{2004} & \multicolumn{2}{|c|}{2005} \\
\hline & Millones $€$ & $\%$ & Millones $€$ & $\%$ & Millones $€$ & $\%$ & Millones $€$ & $\%$ & Millones $€$ & $\%$ \\
\hline Italia & 52,9 & $13,0 \%$ & 56,4 & $12,3 \%$ & 50,0 & $10,3 \%$ & 53,3 & $9,9 \%$ & 57,9 & $11,3 \%$ \\
\hline Egipto & 32,8 & $8,1 \%$ & 35,1 & $7,7 \%$ & 41,2 & $8,5 \%$ & 47,2 & $8,8 \%$ & 49,7 & $9,7 \%$ \\
\hline Portugal & 22,4 & $5,5 \%$ & 21,7 & $4,7 \%$ & 23,6 & $4,9 \%$ & 24,9 & $4,6 \%$ & 25,3 & $4,9 \%$ \\
\hline Polonia & 14,8 & $3,6 \%$ & 15,4 & $3,4 \%$ & 19,0 & $3,9 \%$ & 23,6 & $4,4 \%$ & 22,1 & $4,3 \%$ \\
\hline Indonesia & 28,6 & $7,0 \%$ & 34,2 & $7,5 \%$ & 21,8 & $4,5 \%$ & 21,8 & $4,1 \%$ & 16,6 & $3,2 \%$ \\
\hline
\end{tabular}

Fuente: AEAT. Base de Datos de Comercio Exterior. Cámaras de Comercio.

fritas para la cerámica nacional fueron de 74 millones de euros. Las importaciones provienen de países europeos como Italia, que aporta el 38\% de las importaciones, siguiendo, con la mitad o menos, Alemania y Países Bajos. Europa es el origen
2006 apuntan por primera vez un incremento medio del 9\%, apoyándose positivamente en los esmaltes $(+5 \%)$ y en las fritas $(+12 \%)$, con reducción en colores $(-9 \%)$.

De cara al futuro, los datos de coyuntura indican que

TABLA VI. COMPOSICIÓN DE LAS EXPORTACIONES DE FRITAS, ESMALTES Y COLORES. AÑOS 2000 Y 2005

\begin{tabular}{|c|c|c|c|c|c|c|c|c|c|}
\hline & & \multicolumn{4}{|c|}{ Año 2000} & \multicolumn{4}{|c|}{ Año 2005} \\
\hline & & \multicolumn{2}{|c|}{ Cantidad } & \multicolumn{2}{|c|}{ Valor } & \multicolumn{2}{|c|}{ Cantidad } & \multicolumn{2}{|c|}{ Valor } \\
\hline & Código TARIC & Miles Ton. & $(\%)$ & Mill. $€$ & $(\%)$ & Miles Ton. & $(\%)$ & Mill. € & $(\%)$ \\
\hline Total & 3207 & 590 & 100 & 382 & 100 & 757 & 100 & 513 & 100 \\
\hline Colores & 320710 & 31 & 5 & 83 & 22 & 58 & 8 & 144 & 28 \\
\hline Esmaltes & 320720 & 61 & 10 & 35 & 9 & 153 & 20 & 89 & 17 \\
\hline Lustres & 320730 & 1 & 0 & 2 & 0 & 3 & 0 & 4 & 1 \\
\hline Fritas & 320740 & 497 & 84 & 263 & 69 & 543 & 72 & 277 & 54 \\
\hline
\end{tabular}

Fuente: Elaboración propia. AEAT. Base de Datos de Comercio Exterior. Cámaras de Comercio.

de más del $90 \%$ de las importaciones españolas, aunque están entrando proveedores de terceros países, como es el caso de China, con productos de alto valor unitario (i.e. colores cerámicos).

En definitiva, el saldo comercial de estos productos permanece muy favorable a España con la mayoría de los países, cómo ya se ha indicado la Tasa de Cobertura de las Importaciones en 2005 ha sido de 693\%. No obstante, se observan cambios aun hoy moderados, a causa de la creciente competencia internacional y la irrupción de China en la producción y en el comercio internacional.

Por otra parte, desde 2000 a 2005 se ha incrementado la exportación de los productos con mayor valor añadido (Tabla $\mathrm{VI}$ ), creciendo el peso de los colores y esmaltes frente a las fritas, cuya exportación en unidades físicas apenas ha variado $(+9 \%)$, frente a lo experimentado por los colores $(+87 \%)$ y esmaltes $(+151 \%)$. En resumen, desde el 2000 al 2005, se han producido las siguientes variaciones: a) Aumento en cantidad: $+28 \%$; b) Aumento en Precio medio: $+5 \%$; c) Aumento en Valor: $+34 \%$

Sin embargo, los precios reales no han aumentado. Aunque se inicia un período de grandes incertidumbres al estar las expectativas del sector esmaltero muy condicionadas por la evolución del sector de pavimentos y revestimiento y este del sector de la construcción. Así, el número de viviendas visadas a lo largo del año 2007 se ha reducido prácticamente al 50\%, respecto a las cifras del 2006; por lo que el número de viviendas a construir a lo largo del año 2008 puede estimarse en torno a las 500.000 y previsiblemente experimentará un descenso aún mas acusado a lo largo del año 2009

Los datos oficiales del sector, a través de ASCER, reflejan una situación algo mas positiva. El sector azulejero castellonense cerró el año 2007 con un incremento del 3,5\% de su facturación con respecto a 2006 al sumar ventas por valor de 4.120 millones, aumento de las ventas que ha sido positivo tanto en el mercado doméstico como en el internacional. Esta evolución se ha dado pese a haberse registrado una reducción del 3,85\% su producción al pasar de los 608,4 millones de metros cuadrados en 2006 a los 585 millones de metros cuadrados de 2007. En todo caso parece continuar el descenso iniciado en el 2005 tras los cifras record de $650 \mathrm{M} \mathrm{m2}$ alcanzadas en el período 2002-2005. 
En cualquier caso, ese crecimiento de la facturación responde a que a lo largo de 2007 se realizaron varias revisiones de las tarifas que han permitido repercutir en el precio de venta, parte del importante aumento de los costes. Una política que, según ASCER, deberá repetirse en 2008 para que no se vea afectada la rentabilidad de las empresas.

El 56\% de las ventas de la industria azulejera castellonense ha tenido como destino los mercados internacionales, registrando un aumento del 5,5\% al sumar una facturación de 2.300 millones de euros. En cuanto a las ventas en el mercado nacional, durante 2007 representaron el $44 \%$ lo que implica un crecimiento del $2 \%$, alcanzando los 1.840 millones de euros, un aumento que ha sido algo menor que el experimentado en años anteriores.

A nivel internacional, la Unión Europea se consolida como el principal destino de las exportaciones azulejeras castellonenses. De hecho, la Unión Europea absorbe ya el 50\% de las ventas internacionales. Según los datos facilitados por ASCER destacan de manera muy especial los crecimientos registrados en Francia (11,9\%), Italia (24\%), Grecia $(24,6 \%)$, Reino Unido (4\%), Alemania (2,2\%) y Rumania (37,5\%).

En su conjunto, el continente europeo ha crecido un $14,8 \%$ aproximadamente y representa cerca del $67 \%$ de las exportaciones, el aumento europeo ha compensado la caída de las ventas en Estados Unidos (que supone el 6,6\% del total de exportaciones) derivadas de la fortaleza del euro frente al dólar y a la crisis hipotecaria que está sufriendo.

Se espera que el año 2008 sea un año de consolidación del crecimiento de esta industria en los mercados internacionales, con la Unión Europea, países de Europa del Este, y algunos países del área africana a la cabeza. Esta previsión para el futuro se basaría en la posición de competitividad que tiene el sector español a nivel mundial.

En cuanto al mercado nacional, el motor que más tirará de la demanda será el mercado de la reforma, ya que actualmente hay un amplio parque de viviendas nacionales a ser reformadas.

En cuanto a la tipología de producto, según datos del sector, se estima que el año 2007 se ha alcanzado una cifra algo superior al $30 \%$ en los pavimentos de pasta blanca, y se mantiene la tendencia al alza. De ese 30\%, más de la mitad es material porcelánico, siendo la otra mitad revestimiento poroso y pavimento de gres de monococción. De la porción porcelánica, bastante más de la mitad es ya de porcelánico esmaltado, siendo este producto el que más crece, tanto dentro del porcelánico como de la cerámica blanca, como de las baldosas cerámicas en general. Este dato es positivo para el sector esmaltero puesto que, como se ha indicado, ese tipo de producto es el que consume más cantidad de esmaltes.

En cuanto a la industria italiana más del $80 \%$ del pavimento que produce es porcelánico y, de éste, más del $70 \%$ es esmaltado. El modelo productivo italiano es muy diferente al español dado que no tiene excesivo peso ni la cerámica roja, ni el revestimiento poroso.

Los datos recogidos confirman que, en los últimos años, España se está orientando hacia un modelo más cercano al italiano, dado el mayor margen económico y la mejor aceptación de esos productos en los mercados internacionales.

Lo más significativo es que Italia acaba 2007 con 150 millones de metros cuadrados producidos fuera de la Península Italiana. Sumando esa cifra a la producida interiormente, supera la producción española pero no por mucho.

En cualquier caso, pese a los pronósticos mas positivos expresados por los representantes del sector todo apunta a la continuidad de los factores que afectan negativamente al futuro del sector: apreciación progresiva del euro frente al dólar, la bajada de la construcción en España, la producción masiva en países emergentes, la subida de las energías y las materias primas, lo que se traduce en un cierto pesimismo en los países latinos. Todo apunta a que en estos momentos la producción está muy por debajo de la capacidad productiva y que el año 2008 será complejo y difícil de gestionar.

\section{ESTRUCTURA Y DINÁMICA EMPRESARIAL}

\subsection{Desarrollo y evolución de la industria.}

La industria de esmaltes se puede decir que nace en España después de la guerra civil, en los años cuarenta, tras separarse de algunas azulejeras la sección de elaboración de esmaltes dada la creciente especialización. En un primer momento abastecen a la empresa de procedencia para, posteriormente, abrirse el mercado con otros clientes. El sector sufre un impulso decisivo en Castellón a partir de la década de los 60, cuando los citricultores y el comercio citrícola invierten sus excedentes en la industria del azulejo y en la de fritas. Se quiere invertir en una actividad tradicional en la comarca que se ve impulsada por una demanda creciente ante el importante proceso de urbanización que tiene lugar en dicha década.

Las fritas siempre se han usado en cerámica, así hasta los años veinte (17), los esmaltes se preparaban en compartimentos de los propios hornos morunos o árabes (las calcinas) donde se fundía óxidos de plomo con sílice. Era una operación manual del oficial esmaltador. En los años treinta, en Manises que se especializa en mayor medida en loza sanitaria, se cubre con esmalte opaco blanco piezas de arcillas (palanganas, lavabos, etc.), mientras que la producción del azulejo industrial se va a concentrar en Castellón. En este sector aparecen determinadas innovaciones como las prensas de fricción y los hornos de pasajes (el primer horno continuo) para cocer el bizcocho con el esmalte encima, saliendo con la cubierta vitrificada; los primitivos hornos morunos intermitentes se dejan inicialmente para cocer solamente el bizcocho). La expansión de la industria del azulejo está asociada, a partir de los años 40 a estos hornos, a los que siguirían el horno canal y el horno túnel (el primero de los cuáles se instalaría en Ribesalves 1960).

En este contexto surge la nueva industria. La Tabla VII refleja la cronología del nacimiento de las empresas hoy existentes, así como de las instituciones y asociaciones relevantes para el sector cerámico.

En las primeras décadas del siglo $X X$ nacen y se desarrollan tres de las empresas extranjeras presentes en el sector, Ferro, Pemco y Colorobbia. Las dos primeras se venían dedicando a fabricar esmalte porcelánico (porcelain enamel) para recubrir materiales metálicos constituyentes de cocinas, electrodomésticos, sanitarios, etc.

Tras la Guerra Civil española, en un contexto de autarquía, muchas empresas cerámicas tuvieron problemas de suministro de colorantes y pigmentos de calidad y sintieron la necesidad de crear instalaciones para su fabricación al efecto de sustituir las importaciones que no podían conseguir. A finales de este periodo autárquico, se promovió por agentes del sector la creación del Instituto de Cerámica y Vidrio (CSIC) en 1958 y de la Sociedad de Cerámica y Vidrio en 1960, instituciones de apoyo al sector, que por entonces intuía el desarrollo de sus 
TABLA VII. FORMACIÓN DE LA INDUSTRIA DE FRITAS, ESMALTES Y COLORES CERÁMICOS, E INSTITUCIONES CONEXAS.

\begin{tabular}{|c|c|}
\hline Fechas & Empresas, Instituciones y Asociaciones \\
\hline Antes de 1940 & $\begin{array}{l}\text { Ferro Corporation (matriz), Colorobbia Italia (matriz), } \\
\text { Pemco Internacional (matriz) }\end{array}$ \\
\hline Años $40-50$ & CC Elcom, Esmaltes, Ferro Spain, CC Bonet, CC Lahuerta \\
\hline Años 60 & $\begin{array}{l}\text { Sociedad Española de Cerámica y Vidrio (1960), Instituto } \\
\text { de Cerámica y Vidrio CSIC(1962), Torrecid, Vernis, } \\
\text { PRODESCO, IQT Instituto de Química Técnica (1969) } \\
\text { (antecedente del ITC) }\end{array}$ \\
\hline Años 70 & $\begin{array}{l}\text { Fritta, CC Tortosa, Vidres, Esmaldur, Esmalglass, ATC } \\
\text { Asociación de Técnicos Cerámicos (1976), Asociación } \\
\text { sectorial ANFFEC (1977), }\end{array}$ \\
\hline Años 80 & $\begin{array}{l}\text { Al Farben, Euroarce (Color Smalt), Colores Cerámicos, } \\
\text { Colores Olucha, Quimicer. CEVISAMA, feria sectorial } \\
\text { (1982). AICE Asociación de Investigación de la Industria } \\
\text { Cerámica. (1984). }\end{array}$ \\
\hline Años 90 & $\begin{array}{l}\text { U. Jaume I (UJI), QUALICER, FP en Tecnología Cerámica. } \\
\text { Coloronda, Johson Matthey Ceramics, Cerfrit, Wendel Email } \\
\text { Ibérica, Pemco Esmaltes, Vitricol, ITACA, San Alf Químicas. }\end{array}$ \\
\hline
\end{tabular}

Fuente: Elaboración propia. SABI y webs corporativas.

actividades en el campo, sobre todo, de la vivienda, con el apoyo del Instituto Nacional de la Vivienda.

A partir de los años 60 se inicia una secuencia inacabada de constitución de empresas que, hasta la última década del siglo XX y primeros años del actual, van añadiendo cuotas de producción, sin solución de continuidad. Obsérvese que sólo en la última década del siglo se crean ocho nuevas empresas fabricantes (algunas de ellas por adquisición o absorción de otras preexistentes), incrementándose el número de hornos, y otras más elaboradoras y comercializadoras de esmaltes. El crecimiento de la producción es elevado y sostenido y, a excepción de un ligero estancamiento en 1979-80, ha sido capaz de sortear todas las crisis económicas internas e internacionales.

El distrito cerámico de Castellón crece y aprende creciendo. A principio de los años 70 se toman decisiones transcendentales, en el subsector se empieza a contratar técnicos, en particular químicos. Enfrentada a esa misma expansión la industria italiana será más conservadora e incorporará a menos técnicos.

Dos agentes clave para el sector son: la empresa Ferro Spain y el ITC, Instituto de Tecnología Cerámica (y su antecesor IQT, Instituto de Química Técnica). Ferro contrató por primera vez en el sector a técnicos que más tarde se incorporaron a otras muchas empresas; de Ferro salieron por ejemplo los técnicos que crearon la empresa Esmalglass. El ITC ve la necesidad de preparar técnicos para la industria y asume el reto, impulsando los estudios profesionales y universitarios e impartiendo cursos específicos.

En momentos de crisis económica, con el sector madurando, nace en 1976 la ATC, Asociación de Técnicos Cerámicos, que actualmente agrupa a 650 profesionales (el $80 \%$ de los del distrito), y en 1977, ANFFECC, la asociación sectorial, al amparo de la entonces reciente Ley de Asociaciones, formada por un conjunto de empresarios del esmalte, para la defensa de sus necesidades e intereses colectivos. Fueron diecinueve empresas fundadoras de las que la mayoría siguen existiendo en la actualidad.

A partir de los 80, se desarrollan las actividades de la Universitat Jaime I en los temas cerámicos fundamentalmente impulsadas por el ITC, dado que la mejora de la formación contribuye a una mejor vertebración del sector. Las enseñanzas aplicadas al sector, tanto a nivel universitario como de
Formación Profesional, reciben un fuerte impulso, así como las actividades de I+D, como luego se expondrá.

La Tabla VIII recoge en síntesis tres fases observadas en desarrollo del sector. En una secuencia temporal se describen las mismas de acuerdo con una serie de dimensiones que pretenden recoger el amplio abanico de variables descriptoras. Se considera, por ejemplo, el contexto socio-político, y una serie de aspectos como el origen de la empresa, el tipo de productoservicio ofrecido, el contexto tecnológico, aspectos comerciales y otros relevantes que se han denominado estratégicos.

La primera fase alcanza hasta mitad de los años 60, y se caracteriza por el surgimiento del subsector de fritas y esmaltes en un contexto de autarquía económica. Continúa la segunda hasta mitad de los años 90, contemplando en la misma dos subfases con fecha de separación el año 1979, con la crisis industrial que acompaña al comienzo de la democracia. La presencia de la crisis, con su incidencia en los mercados y en el coste de los combustibles, hace necesaria ya en la segunda subfase la aceleración de la renovación de los procesos productivos y el empleo de gas natural en los hornos, como soluciones tecnológicas ahorradoras de gastos energéticos. Ambas subfases tienen en común muchos parámetros que definen un patrón de crecimiento con altas tasas. La tercera fase llega hasta nuestros días, y en ella aparecen ciertos síntomas de agotamiento asociados a la apertura completa del mercado de la UE a partir del 2005, los problemas de competencia derivados de la globalización y más recientemente la influencia del cambio de ciclo en la construcción.

Un aspecto de especial relevancia que interesa resaltar es el rápido progreso tecnológico que ha sufrido el sector cerámico, que ha sido impulsado en gran medida por innovaciones procedentes del subsector esmaltero. En este sentido se expresan los fabricantes de esmaltes han participado en la difusión del nuevo procedimiento de monococción dentro del sector cerámico (18). Su papel también ha sido resaltado por el ITC.

En el caso de Italia, el desarrollo de su industria se retrasó en los 70 con respecto a España, a causa de tener mayores restricciones medioambientales y contar con menos técnicos bien formados. Por estas fechas en Italia se establece la bicocción con multiestratos, y pronto, desde finales de los 70 introducen (a partir de tecnología industrial norteamericana) la monococción con monoestrato, con la que se incrementa mucho la productividad. Hay que resaltar que es Italia es quien pone en marcha no sólo la monococción en monostrato, factor clave en los incrementos de productividad, sino también toda la tecnología asociada de hornos que la industria española, a pesar de diversos intentos, no es capaz de desarrollar. A consecuencia de ello, el sector arrastrará una dependencia muy acusada de la industria de bienes de equipo italiano y no tendrá capacidad, ya en la tercera fase analizada, para de suministrar fábricas "llave en mano".

La monococción en monostrato tecnología no era aplicable directamente a la fabricación del azulejo, requería atomizar una arcilla más pura y obtener unos esmaltes diferentes. Como elemento derivado pero distintivo a la tecnología italiana, en Castellón y se consiguió la cocción monoporosa, es decir la monococción para el revestimiento de pared. Este tipo de material requiere de una arcilla distinta del pavimento, la pasta tiene que ser porosa y el esmalte adecuado también es diferente, tiene que adaptarse a la pasta base y a los parámetros térmicos del proceso de cocción nuevo.

Este desarrollo, la monoporosa, sí ha supuesto para el 
TABLA VIII. LA INDUSTRIA DE FRITAS, ESMALTES Y COLORES CERÁMICOS. DESARROLLO Y EVOLUCIÓN EN ESPAÑA.

\begin{tabular}{|c|c|c|c|}
\hline & Fase Inicial. & Fase Intermedia & Fase Actual \\
\hline & Hasta los 60 (1965) & 1966-95. & Desde 1995 \\
\hline $\begin{array}{l}\text { Contexto socio- } \\
\text { político }\end{array}$ & $\begin{array}{l}\text { Autarquía. Dificultades de exportación y de } \\
\text { suministro de ciertas materias primas. }\end{array}$ & $\begin{array}{l}\text { Apertura exterior. Crecimiento de la } \\
\text { construcción. Crisis industriales. Dos } \\
\text { subfases: 1966-79 y 1980-95 }\end{array}$ & $\begin{array}{l}\text { Incorporación a la Unión Europea y a la } \\
\text { Unión Monetaria. Crecimiento intenso de la } \\
\text { construcción. Globalización y Protocolo de } \\
\text { Kyoto. }\end{array}$ \\
\hline $\begin{array}{l}\text { Origen de la } \\
\text { empresa }\end{array}$ & $\begin{array}{l}\text { Preferentemente desde la industria cerámica } \\
\text { tradicional }\end{array}$ & Desde la cerámica, técnicos y multinacionales & $\begin{array}{l}\text { Técnicos y especialistas químicos. } \\
\text { Multinacionales de los recubrimientos. }\end{array}$ \\
\hline $\begin{array}{l}\text { Aspectos del } \\
\text { producto y del } \\
\text { servicio }\end{array}$ & $\begin{array}{l}\text { La mayoría de las cerámicas elaboraban } \\
\text { sus propios esmaltes y colores. Productos } \\
\text { genéricos, como el cerámico al que va } \\
\text { destinado: unas pocas fritas genéricas } \\
\text { para el esmaltado; pigmentos y colorantes } \\
\text { purificados }\end{array}$ & $\begin{array}{l}\text { Primeras inquietudes acerca de la calidad } \\
\text { y del diseño. Fritas y esmaltes y colores } \\
\text { variados (todos adaptados a los nuevos } \\
\text { sistemas productivos, ampliación del rango } \\
\text { de temperatura de trabajo y nuevas materias } \\
\text { primas). }\end{array}$ & $\begin{array}{l}\text { Diversificación. Productos para el } \\
\text { porcelánico y pasta blanca. Catálogo amplio } \\
\text { de fritas, esmaltes y colores, con distintas } \\
\text { composiciones y especificaciones de uso. } \\
\text { Soluciones especificas para el cliente. } \\
\text { Diseños bajo procedimientos variados para } \\
\text { decoración. }\end{array}$ \\
\hline $\begin{array}{l}\text { Aspectos } \\
\text { tecnológicos }\end{array}$ & $\begin{array}{l}\text { Tecnología tradicional: Del horno moruno } \\
\text { (uso de leña y residuos agrícolas) a los } \\
\text { hornos continuos (de pasajes, de canal, con } \\
\text { fuel-oil). Mecanización prensas. Paso del } \\
\text { minio, la sosa y las arenas locales al uso } \\
\text { progresivo de otros fundentes, zirconio y } \\
\text { boro. }\end{array}$ & $\begin{array}{l}\text { Desarrollo tecnológico del fritado y del } \\
\text { esmaltado. Hornos de túneles y de rodillos. } \\
\text { Bicocción ( } 1^{a} \text { subfase) e implantación de la } \\
\text { monococción }(\mathrm{m}) \text { y m. porosa ( } 2^{\mathrm{a}} \text { subfase). } \\
\text { Atomización. Cogeneración. Nuevos hornos } \\
\text { fritas. Empleo del gas natural. Pastas vía } \\
\text { húmeda. }\end{array}$ & $\begin{array}{l}\text { Tecnologías aplicadas a diseños y } \\
\text { composiciones. Decoraciones bajo métodos } \\
\text { diversos. Desarrollo de Centros de I+D. } \\
\text { Intensificación de la cooperación tecnológica } \\
\text { con ITC, UJI, etc. Desarrollo de esmaltación a } \\
\text { seco (doble carga, doble prensa). }\end{array}$ \\
\hline $\begin{array}{l}\text { Aspectos medio- } \\
\text { ambientales }\end{array}$ & $\begin{array}{l}\text { Problemas de salud laboral y medio- } \\
\text { ambientales (m-a) con óxidos metálicos y } \\
\text { polvo ambiental }\end{array}$ & $\begin{array}{l}\text { Primeras inquietudes sobre el medio } \\
\text { ambiente y mejora continua en los temas de } \\
\text { salud y m-a }\end{array}$ & $\begin{array}{l}\text { Adecuación a mayores exigencias legales. } \\
\text { Control y prevención de emisiones. Adopción } \\
\text { BATs. }\end{array}$ \\
\hline $\begin{array}{l}\text { Aspectos } \\
\text { comerciales }\end{array}$ & $\begin{array}{l}\text { Mercado interior con desarrollo lento. } \\
\text { Autosuministro. Aisla-miento tecnológico. } \\
\text { Hacia final del periodo, inicio de } \\
\text { liberalización. }\end{array}$ & $\begin{array}{l}\text { Desarrollo del mercado interior, con inflexión } \\
\text { en 1978-79 y 89-91, progresos intensos en } \\
\text { exportaciones. }\end{array}$ & $\begin{array}{l}\text { Expansión exterior, con implantación } \\
\text { en nuevos países ceramistas y en zonas } \\
\text { productoras de m. p. Exportación iguala y } \\
\text { supera mercado interior }\end{array}$ \\
\hline $\begin{array}{l}\text { Aspectos } \\
\text { estratégicos }\end{array}$ & $\begin{array}{l}\text { Independización de la ceramista matriz y } \\
\text { ampliación de clientela fuera del grupo. } \\
\text { Aprovechamiento de recursos locales, dado } \\
\text { el régimen autárquico. }\end{array}$ & $\begin{array}{l}\text { Creación ITC para investigación y formación. } \\
\text { Mejora energética. Control del color e } \\
\text { integración de empresas de pigmentos }\end{array}$ & $\begin{array}{l}\text { Investigación sobre aditivos especiales. } \\
\text { Integración de empresas. Inversión en } \\
\text { extractivas y elaboración de materias primas. }\end{array}$ \\
\hline
\end{tabular}

Fuente: Elaboración propia

subsector español una ventaja estratégica, dado que llegado el momento del desarrollo cerámico intenso en otros países, el mercado se desarrolla primero a partir de revestimientos más que de pavimentos.

\subsection{La industria italiana.}

En Italia, como en España, la fabricación de fritas, esmaltes y colores cerámicos siempre ha sido una actividad practicada tradicionalmente en el seno de las propias empresas cerámicas. La separación de esta actividad se inició en Italia a principios del siglo XX, especialmente en el seno de la cerámica de tipo artístico, fuera de la Emilia Romagna (Toscana, Véneto). Es a partir de finales de los 60 y en los 70 cuando se identifica el sector por externalización de la actividad dentro del distrito de Sassuolo, especializado en pavimentos cerámicos.

\subsubsection{Estructura productiva}

El perfil adoptado por el sector se ha debido, además de a la decisión de los ceramistas de externalizar esta actividad, a la necesidad intensa de novedades constantes en el producto cerámico, y a los cambios profundos habidos en el propio proceso de producción cerámica.
Las empresas del colorificio surgen, primero, por una iniciativa de tipo local (correspondiendo bien a las propias empresas cerámicas, o bien a técnicos de las mismas), y asimismo por iniciativa ajena al distrito, tanto por actuaciones de las multinacionales de la química -que vienen a diversificar su portafolio de productos, como en el caso español - y también, con empresas españolas que, además de pretender abrir nuevos mercados, les interesa tomar ideas y soluciones para transferirlas al propio mercado español (19).

En la Tabla IX se relacionan las empresas de este subsector que operan en Italia, por orden de facturación.

El número de empresas en el colorificio italiano (32 según lo expuesto) es, en principio, algo mayor que el español, no obstante, seria inferior si se considera que la cifra anterior incluye también empresas dedicadas sólo a pigmentos y colores (como Inco) y las dedicadas a los aditivos cerámicos o que sólo prepararan esmaltes y decoraciones (caso de Ceramvetro, DEF, Decograf, etc.), sin fabricar sus componentes, que en principio no se han incluido en la relación de la industria española. A tenor de algunas opiniones (15), el número de fabricantes de fritas en Italia debe ser aparentemente menor, asignando a Italia sólo nueve instalaciones (21 en España) y en Europa aproximadamente un total de cuarenta y dos establecimientos. No obstante, algunas referencias 
TABLA IX. FACTURACIÓN DEL SUBSECTOR ITALIANO DE FRITAS, ESMALTES Y COLORES. MILLONES DE EUROS.

\begin{tabular}{|l|c|c|c|}
\hline Empresa & 2000 & 2001 & 2002 \\
\hline Ferro Italia & 66,1 & 64,4 & 106,3 \\
\hline Colorobbia Italia & 91 & 105,1 & 104 \\
\hline Johnson Matthey Italia & 63,1 & 66,3 & 66,3 \\
\hline Cerdec Italia & 66,1 & 59,2 & n.d. \\
\hline Smalticeram Unicer & 33,8 & 38,1 & 43 \\
\hline Colorobbia & 35,7 & 32 & 33,5 \\
\hline Colorveggia Reire & 24,5 & 24,1 & 24,5 \\
\hline Esmalglass & 18,8 & 18,4 & 19,1 \\
\hline Inco & 13,5 & 13,6 & 18,5 \\
\hline Cover & 19,7 & 18,6 & 16,3 \\
\hline Ramacolor & 16,4 & 18,2 & 15,9 \\
\hline Intercolor & 7,9 & 9,4 & 15,7 \\
\hline Sicer & 14,2 & 13,6 & 15,2 \\
\hline Torrecid & 10,4 & 12,4 & 13,5 \\
\hline Reimbold \& Strick Italia & 11,4 & 10,8 & 11,7 \\
\hline Vetriceramici & 8,6 & 9,6 & 11,6 \\
\hline Cer.Ser & 9,2 & 8,4 & 10 \\
\hline Coloritalia & 9 & 7,5 & 9,8 \\
\hline Garcolor & 8,5 & 7,3 & 8,1 \\
\hline Smaltitalia & 8,7 & 8 & 7,5 \\
\hline Torriana & 7,9 & 6,9 & 7,1 \\
\hline Def di Doni & 7,7 & 7 & n.d. \\
\hline Smalti per Ceramiche S.P.C. & 5,5 & 6,3 & 6,9 \\
\hline A.S. & 8,1 & 6,2 & n.d. \\
\hline Eurocolor & 3,8 & 3,9 & 4,5 \\
\hline Sicer Internacional & 0 & 3,7 & n.d. \\
\hline Ceramvetro Gold & 3,2 & 2,5 & 2,8 \\
\hline Fritta Italia & 2 & 1,9 & 2,3 \\
\hline Vernis Italia & 1,7 & 2,1 \\
\hline Decograf & 1,6 & 1,6 \\
\hline Cerev & 589,5 & n.d. \\
\hline Mph & & \\
\hline TOTAL & 3,4 & 0,3 \\
\hline & & & \\
\hline
\end{tabular}

Fuente: (20)

(19) mencionan hasta veinticuatro empresas en 2005; todas ellas ubicadas en Sassuolo excepto dos de ellas en la Toscana (Colorobbia y Cover) y otra de Rávena (Vitroceramici). Entre las de mayor facturación están empresas también presentes en el mercado e industria españoles (Ferro Italia, Colorobbia, Johnson Matthey Ceramics y Smalticeram Unicer) con fabricación propia. Se hallan presentes numerosas filiales de empresas españolas (Esmalglass, Torrecid, Fritta, Vernis, CC Bonet (Cer.Ser), etc.), que se dedican a importar y preparar esmaltes sin fabricación propia. Otras empresas pertenecen a los ceramistas (Ramacolor, Garcolor, Arco, de los grupos ceramistas Marazzi, Gardeinia, e Iris, respectivamente), caso que no se da en España.

Otras empresas que, sin ser españolas, están también presentes en nuestro mercado e industria (Ferro, Colorobbia, Johnson Matthey Ceramics, actual Endeka Ceramics) con fabricación propia.

La facturación, entre los años 2000 y 2002, se mantuvo en torno a los 580 millones de euros, bastante inferior a la del sector español, un $70 \%$, aproximadamente, valor que se reduce a un $50 \%$ si se tiene en cuenta la facturación expresada por algunos autores (19) (Tabla X). Se observa asimismo que, como en el caso español, existe un amplio abanico de dimensiones empresariales, predominando numéricamente las empresas pequeñas, resultando que la mitad de estas empresas no supera los 10 millones de euros de facturación. La facturación en 2004 ascendió a 518 millones de euros, bastante inferior a la del sector español (un $50 \%$, aproximadamente). Es importante destacar que el colorificio italiano se ve penalizado por el hecho de que en su cerámica tiene gran relevancia el gres porcelánico, al que no se le aplica habitualmente el esmaltado. En efecto, Italia tiene una producción cerámica en torno a los 600 millones de $\mathrm{m} 2$, siendo mayoritaria la cerámica de piso-pavimento y marginal la de revestimiento. El gres porcelánico representa actualmente el $60 \%$ de la producción, creciendo desde sus inicios hace una década. Se emplea para su elaboración la pasta blanca y se le aplica unos tratamientos especiales (pulido entre ellos). Una parte bastante estable, en torno al $20-25 \%$, se dedica al porcelánico técnico, producto estrella de la cerámica italiana, que requiere el empleo de unas materias primas especiales y caras. Entre el 35-40\% de la producción es porcelánico esmaltado que requiere materias primas menos puras (y por tanto mas baratas); se trata de una fracción que crece a costa de otros productos menos sofisticados, como el pavimento clásico de monococción (21). En España se usa mucho la pasta roja tanto para azulejo como para baldosas. Pero crece el consumo de la pasta blanca porque sus productos tienen más prestigio y valor económico. El producto medio italiano tiene un precio de exportación muy superior al español o al de otros países: entorno a $11 €, 6 €$ y $3 €$ el metro cuadrado, respectivamente para el producto italiano, español y de terceros países, según datos del año 2006.

Además de la especialización cerámica italiana, también incide de forma directa en el colorificio, la demanda del mercado interior. En Italia el consumo para piso es mas alto que en España pero menor para revestimientos. La incidencia en el consumo de esmaltes está asociada a la cantidad y especialidad de los productos que consumen los distintos productos cerámicos. Estos varían mucho:

A) En azulejos y pavimento no porcelánico siempre se utilizan esmaltes y su cantidad depende del acabado, cuanto mejor acabado y más caro es el azulejo más esmalte lleva incorporado así los acabados en mate utilizan entre 0.5 y 0.8 $\mathrm{Kg} . / \mathrm{m}^{2}$, y los acabados en brillo entorno a los $1.25 \mathrm{Kg} . / \mathrm{m}^{2}$.

B) En porcelánico, el denominado gres porcelánico técnico, emplea mucho color que lo embellece, pero no emplea fritas ni esmaltes dado que apenas tiene porosidad ni impermeabilidad en las calidades altas. En el gres porcelánico esmaltado, se emplean cantidades variables de esmalte para incrementar las aplicaciones decorativas y estéticas y que, además, mejoran la impermeabilidad, de este modo los acabados en mate utilizan entre 0.5 y $0.8 \mathrm{Kg} . / \mathrm{m}^{2}$, y los acabados en brillo entorno a los $2 \mathrm{Kg} . / \mathrm{m}^{2}$.

\section{Evolución del sector en el distrito de Sassuolo.}

El colorificio ha acompañado a las empresas ceramistas italianas allá donde han ido estableciendo sus unidades productivas, buscando además aumentar el número de sus clientes y elevar el nivel de los servicios ofrecidos. Esto es válido tanto en lo que se refiere al proceso de internacionalización más reciente, como al desarrollo mismo de la industria en Italia.

Como se ha expresado, la cerámica artística es la rama que primero demanda externalizar estos productos. Con tecnología básica se llega a finales de los 60 con el sector perfectamente identificado. Resumidamente se puede expresar que, desde 
los 60, la demanda inicia un crecimiento rápido con tasas elevadas que se mantuvieron hasta los 90, cuando redujeron su ritmo. A partir de los 2000 la demanda se ha estabilizado. En este periodo, hubo momentos críticos, por la elevación de los costes energéticos.

Inicialmente, el incremento de la demanda en Sassuolo (Emilia Romagna), especializado en la producción de pavimento cerámico, produce un acercamiento a su distrito del sector de esmaltes tanto de localización física como de relevancia en términos de mercado y retos tecnológicos. Las empresas del colorificio (Colorobbia, Fanciullacci, Cover, toscanas ellas) establecen su representación comercial en el distrito, luego una asistencia técnica, con laboratorios y finalmente levantan planta de fabricación en una secuencia continua. En Italia existen grupos ceramistas que tienen su propio colorificio (Ramacolor, Garcolor, Arco, de los grupos Marazzi, Gardeinia, e Iris, respectivamente) dedicado al autoaprovisionamiento en distinto grado, además de algunos técnicos (caso de Smalticeram Unicer).

Asimismo, en este contexto de alta demanda, surgen numerosos agentes intermedios (el miscelifici), que preparan esmaltes comprando semielaborados a los fabricantes. Algunos de estos especialistas llegan a integrarse en el colorificio, aumentando así el nivel de los servicios al ceramista.

A finales de los 70 y principios de los 80, comienza la llegada de multinacionales de la Química (Ferro, Degussa, Bayer y más adelante Pemco, Johnson Matthey) normalmente adquiriendo empresas establecidas e iniciando la modernización del colorificio con innovación, laboratorios de análisis y departamentos técnicos. En momentos de crisis o cuando se producen los grandes saltos tecnológicos, con las consiguientes necesidades de fuertes inversiones, se producen reordenaciones del sector con fusiones (caso de Colorveggia) o con adquisiciones, como efectuaron Ferro y J. Matthey. Las empresas españolas se introducen posteriormente, con Esmalglass (en alianza con una empresa local) y seguidamente, en los año 90, Torrecid, CC Bonet, Fritta y Vernis.

Desde finales de los años 80, con la llegada del gres porcelánico, se reactivó la demanda de colores y ello afectó positivamente al colorificio. Posteriormente, el surgimiento del porcelánico esmaltado a costa de la baldosa tradicional, se traduce en un menor consumo de esmalte, por lo que el sector se está resintiendo económicamente.

Últimamente, la diferenciación necesaria en el producto cerámico se centra en buena parte el aspecto gráfico y serigráfico (aplicación del esmalte), donde intervienen otros agentes (estudios gráficos, empresas de serigrafía, etc.). Estos agentes se relacionan bien con especialistas del tipo de los miscelifici, de lo que resulta que el colorificio está perdiendo poder competitivo.

Otra de las estrategias de supervivencia seguidas por el sector ha sido la internacionalización. Ésta comenzó en los años 80 con las primeras exportaciones; continúa en los 90, intensificándose las exportaciones e iniciándose la producción en el exterior que se mantiene hoy en día.

La salida al exterior ha sido objeto de una minoría de empresas del colorificio, pero ha tenido la virtud de reducir su dependencia de la clientela local y nacional. El colorificio facturó el $62 \%$ dentro del distrito de Sassuolo, mientras que los ceramistas italianos del distrito adquirieron al colorificio hasta el $88 \%$ del total de sus compras de esmaltes.(19)

La Tabla $X$ revela cifras de interés sobre el mercado italiano. El colorificio no exporta más del $30 \%$ en valor de su facturación, porcentaje muy inferior al practicado por el subsector español, y por la cerámica italiana que alcanza hasta el $70 \%$ de su producción. La facturación aquí reflejada, unos 518 millones de euros, es inferior a la aportada en la Tabla IX, cercana a 600 millones de euros, la diferencia hay que atribuirla a que las fuentes son distintas y sus respectivos colectivos de referencia, también. En la Tabla X se tienen en consideración 24 empresas del colorificio. El sector sigue registrando un notable grado de dependencia con respecto al sector cerámico italiano, pero dicha dependencia tiende ligeramente a reducirse.

TABLA X. EVOLUCIÓN DE LAS INDUSTRIAS CERÁMICA Y EL COLORIFICIO ITALIANO. FACTURACIÓN EN MERCADO INTERIOR Y EXPORTACIÓN. 2000 Y 2004.

\begin{tabular}{|c|c|c|c|c|c|}
\hline & \multirow{2}{*}{ Año } & Mercado interior & \multicolumn{2}{|c|}{ Exportación } & Facturación \\
\hline & & Mill.€ & Mill.€ & $(\%)$ & Mill.€ \\
\hline \multirow{2}{*}{$\begin{array}{c}\text { Cerámica } \\
\text { italiana }\end{array}$} & 2000 & 1544 & 3684 & $70 \%$ & 5228 \\
\hline & 2004 & 1509 & 3864 & $72 \%$ & 5372 \\
\hline \multirow{2}{*}{ Colorificio } & 2000 & 371 & 117 & $24 \%$ & 488 \\
\hline & 2004 & 368 & 150 & $29 \%$ & 518 \\
\hline
\end{tabular}

Fuente: Asstropiastralle y (19)

\subsection{Estrategias empresariales.}

La industria de fritas, colores y esmaltes, que surgió por la externalización de tareas productivas del sector cerámico, ha seguido en la línea de recoger nuevas tareas externalizadas por los ceramistas, con una actitud de servicio a sus clientes finales.

Dos líneas estratégicas fundamentales han sido desarrolladas para sobrevivir y adaptarse a lo que el sector ceramista les ha reclamado. Por un lado, una estrategia continuada de innovación (que se desarrollará en el siguiente apartado), basada en la I+D fundamentalmente, y en el apoyo decidido a las innovaciones surgidas en subsectores colaterales (11).

Por otro lado, y en coherencia con lo anterior, para poder rentabilizar la $\mathrm{I}+\mathrm{D}$ y todas las inversiones requeridas en el esfuerzo innovador las empresas líderes han buscado el crecimiento de tipo orgánico buscando sinergias, ampliando la escala de sus actividades en áreas colindantes con las iniciales, en dirección tanto horizontal como vertical. De este modo han ampliado tanto la gama de sus productos (fritas, esmaltes, colores, aditivos, etc.) como la cartera de clientes: azulejeros, fabricantes de pavimento con diferentes tecnologías, para la vajillería, cerámica artística, etc. En otra dirección, han buscado controlar el suministro de sus materias primas para ellos o para sus clientes: explotaciones mineras y tratamiento de minerales (atomizadoras, zirconio, alúmina, etc.). En este sentido, se ha valorado positivamente la actuación de los empresarios azulejeros ya que, desde el primer momento, no han ahorrado esfuerzos de inversión, primando siempre la proximidad o cercanía, tanto sectorial como geográfica (14).

La internacionalización del sector se inicia desde antiguo mediante la apertura hacia clientes extranjeros, con la exportación a países donde se localizan empresas cerámicas. A estos efectos es útil hacer presencia en los foros internacionales más propicios, así en las ferias Cevisama (Valencia) y Cersaie (Bolonia) comparten espacio las empresas ceramistas y los 
fabricantes de esmaltes (entre otros sectores). Más específica es la feria Tecnargilla (Rimini- Italia) feria dedicada a los colores, materias primas y maquinaria para la cerámica.

A partir de finales de los 80 y en los 90, el sector español se lanza con decisión ha montar establecimientos en el exterior. Los motivos de implantación exterior suelen ser muy variados. Habitualmente se dice buscar reducir los costes: de transporte (de materias primas y/o de productos terminados), de procesado (por existencia de mano de obra más preparada o más barata) o de materias primas (acceso a un suministro privilegiado de alguna o algunas materias primas). Se puede dar casos variados, pero normalmente en todos ellos lo que resalta es la mejora del servicio al cliente, especialmente en rapidez. La proximidad al cliente con presencia física de instalaciones, personal técnico, stocks, etc., es esencial para ampliar cuotas de mercado en una zona donde la baldosa cerámica entra en una espiral de consumo y se desarrolla la cerámica local. También, las nuevas plantas en el exterior sirven de nueva base de operaciones para introducirse en mercados más próximos (por ejemplo, México es interesante para acceder a EEUU) por motivos de proximidad (costes de transporte), de acuerdos comerciales (menores aranceles), etc. El desarrollo de la industria local de esmaltes en los nuevos países productores de cerámica (China, Brasil, etc.) ha hecho que los líderes se orienten allí hacia los segmentos de calidad, que retribuyen mejor el esfuerzo inversor, y en los que su producto es muy valorado.
Las grandes empresas españolas poseen filiales en una veintena de países. Entre los principales localizaciones están, en Europa, Italia, especialmente (con seis filiales de empresas), Portugal (tres) y Reino Unido (tres); en América, destacan Brasil (cinco), México (cuatro) y Estados Unidos (dos); y en Asia, China (cinco) e Indonesia (cuatro).

\subsection{Estructura económico-financiera.}

La Tabla XI recoge el balance de situación agregado para las empresas esmalteras y el de la industria cerámica (código CNAE: 2630), que informan sobre balances presentes a 31 de diciembre del 2005. La industria de esmaltes presenta un activo total de 1.290 millones de euros, lo que supone alcanzar un relevante $23 \%$ del sector cerámico en su conjunto (mayor que el peso relativo del $\mathrm{n}^{\circ}$ de empresas $(7 \%)$ y de trabajadores $(15 \%))$. Curiosamente, el activo de ambas industrias tiene una composición parecida (un $46-48 \%$ para el inmovilizado y $52-54 \%$ para el circulante. En el activo fijo pesa ligeramente más en las empresas esmalteras la fracción de las inversiones financieras fijas (17\% frente al 10\%).

En relación a la financiación del activo, se observa 7 puntos más de autofinanciación en las empresas de fritas que en las azulejeras, con un coeficiente de endeudamiento del $53 \%$ frente al $60 \%$ de la cerámica, apoyándose más este último sector en la financiación a corto. El neto patrimonial es de 610 millones de euros, que es poco más de la cuarta parte $(27 \%)$ del valorado para la cerámica.

TABLA XI. BALANCE DE SITUACIÓN DE LAS INDUSTRIAS DE ESMALTE Y DE CERÁMICA. 31/12/2005

\begin{tabular}{|c|c|c|c|c|c|c|c|c|}
\hline \multirow[b]{3}{*}{ Balance de Situación } & \multirow{2}{*}{\multicolumn{2}{|c|}{ Industria Cerámica (a) }} & \multicolumn{6}{|c|}{ INDUSTRIA DEL ESMALTE } \\
\hline & & & \multicolumn{2}{|c|}{ Total } & \multicolumn{2}{|c|}{$\begin{array}{l}\text { Empresas con menos de } 100 \\
\quad \text { empleados }\end{array}$} & \multicolumn{2}{|c|}{$\begin{array}{l}\text { Empresas con } 100 \text { o más } \\
\text { empleados }\end{array}$} \\
\hline & Mill. $€$ & $(\%)$ & Mill. $€$ & $(\%)$ & Mill. $€$ & $(\%)$ & Mill. $€$ & $(\%)$ \\
\hline ACTIVO TOTAL & 5.584 & $100 \%$ & 1.281 & $100 \%$ & 152 & $100 \%$ & 1129 & $100 \%$ \\
\hline Inmovilizado (I) & 2.580 & $46 \%$ & 624 & $49 \%$ & 56 & $37 \%$ & 568 & $50 \%$ \\
\hline material+ g.instalación & 1.890 & $34 \%$ & 372 & $29 \%$ & 50 & $33 \%$ & 322 & $29 \%$ \\
\hline inmaterial & 146 & $3 \%$ & 26 & $2 \%$ & 2 & $1 \%$ & 28 & $2 \%$ \\
\hline inv.financieras fijas & 544 & $10 \%$ & 223 & $17 \%$ & 4 & $3 \%$ & 219 & $19 \%$ \\
\hline Circulante (C) & 3.005 & $54 \%$ & 657 & $51 \%$ & 96 & $63 \%$ & 561 & $50 \%$ \\
\hline existencias & 1.155 & $21 \%$ & 190 & $15 \%$ & 34 & $22 \%$ & 156 & $14 \%$ \\
\hline deudores & 1.551 & $28 \%$ & 411 & $32 \%$ & 55 & $36 \%$ & 356 & $32 \%$ \\
\hline tesorería & 299 & $5 \%$ & 56 & $4 \%$ & 6 & $4 \%$ & 59 & $5 \%$ \\
\hline NETO PATRIMONIAL & 2.259 & $40 \%$ & 591 & $46 \%$ & 69 & $45 \%$ & 522 & $46 \%$ \\
\hline PASIVO TOTAL & 3.326 & $60 \%$ & 690 & $54 \%$ & 83 & $55 \%$ & 607 & $54 \%$ \\
\hline Pasivo fijo (PF) & 985 & $18 \%$ & 212 & $17 \%$ & 26 & $17 \%$ & 186 & $16 \%$ \\
\hline Acreedores a L.P. & 974 & $17 \%$ & 200 & $16 \%$ & 25 & $16 \%$ & 175 & $16 \%$ \\
\hline otros p.f. & 11 & $0 \%$ & 12 & $1 \%$ & 1 & $1 \%$ & 12 & $1 \%$ \\
\hline Pasivo líquido & 2.341 & $42 \%$ & 477 & $37 \%$ & 57 & $38 \%$ & 421 & $37 \%$ \\
\hline Deudas financieras (DF) & 976 & $17 \%$ & 137 & $11 \%$ & 10 & $7 \%$ & 127 & $11 \%$ \\
\hline Acreedores comerciales & 808 & $14 \%$ & 236 & $18 \%$ & 28 & $18 \%$ & 208 & $18 \%$ \\
\hline O.p.l. & 557 & $10 \%$ & 104 & $8 \%$ & 19 & $13 \%$ & 86 & $8 \%$ \\
\hline \multicolumn{9}{|l|}{ RATIOS } \\
\hline ENDEUDAMIENTO & & $60 \%$ & & $54 \%$ & & $55 \%$ & & $54 \%$ \\
\hline Endeudam.nto a LP (PF/I) & & $38 \%$ & & $34 \%$ & & $46 \%$ & & $33 \%$ \\
\hline E. financiero a $\mathrm{CP}(\mathrm{DF} / \mathrm{C})$ & & $32 \%$ & & $21 \%$ & & $10 \%$ & & $23 \%$ \\
\hline
\end{tabular}

(a) Conjunto empresas CNAE 2640 (unas 400 empresas), con cuentas registradas.

Fuente: SABI. Elaboración propia. 
La Tabla XI nos proporciona información del mismo tipo que la anterior, pero permitiendo ahora comparar las cifras del grupo de empresas esmalteras según tamaños, de cien o más trabajadores frente al resto. Las empresas con más de cien trabajadores recogen el $88 \%$ de la facturación y el $85 \%$ del empleo; también concentran el $88 \%$ del activo total agregado del sector.

Respecto a la composición del activo, dichas empresas concentran una gran parte de la inversión financiera fija (el 98\% del total, 219 millones de euros), que previsiblemente reflejan las fuertes inversiones en empresas subsidiarias (capital de control accionarial), alcanzando el 19\% del activo total frente al $2 \%$ de las pequeñas ( $17 \%$ del promedio). En menor medida, pero también relevante, las empresas con más de cien trabajadores acaparan el activo inmaterial (93\% del total), resultado de su política de promoción comercial, previsiblemente.

La estructura del pasivo resulta bastante homogénea entre ambos grupos de empresas, ya que tanto en las más grandes como en las pequeñas la financiación a largo ocupa el $31 \%$ del pasivo, mientras que el pasivo líquido alcanza el restante $69 \%$. Pero lo más reseñable es que, aun teniendo un grado de endeudamiento parecido $(52 \%-54 \%)$, las grandes apuestan más por el endeudamiento a corto mientras que las pequeñas se decantan más por el endeudamiento a largo.

En la tabla XII se aporta información sobre los gastos, márgenes y resultados comparados de los sectores cerámico y de esmaltes y se comparan de nuevo las cifras de las empresas de este último sector según tamaño.

En primer lugar, podemos observar cómo se alcanzan los resultados ordinarios a partir de la facturación, descontando los gastos. Estos gastos se componen de 1) gastos de personal, 2) materias primas y materiales; 3 ) dotación para amortizaciones del capital; 4) otros gastos de explotación (que vienen a incluir suministros de gas, energía eléctrica, agua, etc.); y 5) gastos financieros y asimilados.

Destaca también la notoria diferencia entre las estructuras de costes de ambas industrias. Las empresas esmalteras gastan proporcionalmente más que la cerámica en materias primas y materiales (58\% frente al $44 \%$ de la facturación respectiva) y proporcionalmente menos en los restantes componentes del gasto (personal -pese a salarios medios más altos-, otros gastos de explotación, amortizaciones y financieros). Las rentabilidades económica y financiera, así como las ratios de cashflow y valor añadido por empleado, resultan superiores en la industria esmaltera que en la cerámica.

Parece claro que las materias primas son un componente del coste muy relevante en el caso de las esmalteras. Si nos fijamos en los gastos operativos directos (de fabricación), se observa que las materias primas vienen a representar más del $60 \%$ del total. El precio de las mismas será pues condicionante de la rentabilidad final.

En la Tabla XII observamos, además, los gastos, los resultados y su composición en el caso de las empresas de

TABLA XII. ESTRUCTURA DE GASTOS DE LAS INDUSTRIAS DE ESMALTES Y DE CERÁMICA. 2005

\begin{tabular}{|c|c|c|c|c|c|c|c|c|}
\hline \multirow[b]{3}{*}{ CONCEPTO } & \multirow{2}{*}{\multicolumn{2}{|c|}{ Industria Cerámica (a) }} & \multicolumn{6}{|c|}{ INDUSTRIA DEL ESMALTE } \\
\hline & & & \multicolumn{2}{|c|}{ Total } & \multicolumn{2}{|c|}{$\begin{array}{l}\text { Empresas con menos de } 100 \\
\text { empleados }\end{array}$} & \multicolumn{2}{|c|}{$\begin{array}{l}\text { Empresas con } 100 \text { o más } \\
\text { empleados }\end{array}$} \\
\hline & & & & & & & & \\
\hline Facturación (d) (mill. de €) & 4.165 & & 990 & & 123 & & 867 & \\
\hline Empleados & 28.884 & & 4.007 & & 609 & & 3.398 & \\
\hline ESTRUCTURA DE GASTOS & Mill. $€$ & $(\%)$ & Mill. $€$ & $(\%)$ & Mill. $€$ & $(\%)$ & Mill. $€$ & $(\%)$ \\
\hline Personal & 911 & $23 \%$ & 154 & $16 \%$ & 22 & $18 \%$ & 132 & $16 \%$ \\
\hline Mat. primas y materiales & 1.755 & $44 \%$ & 551 & $58 \%$ & 64 & $53 \%$ & 487 & $59 \%$ \\
\hline Amortizaciones & 255 & $6 \%$ & 49 & $5 \%$ & 6 & $5 \%$ & 43 & $5 \%$ \\
\hline Otros gastos de explotación & 972 & $24 \%$ & 178 & $19 \%$ & 28 & $23 \%$ & 150 & $18 \%$ \\
\hline G. financieros y asimil. (c) & 86 & $2 \%$ & 13 & $1 \%$ & 1 & $1 \%$ & 12 & $1 \%$ \\
\hline TOTAL Gastos Ordinarios & 3.979 & $100 \%$ & 945 & $100 \%$ & 120 & $100 \%$ & 825 & $100 \%$ \\
\hline RESULTADOS Y RATIOS. & Mill. $€$ & $\% \mathrm{~s} /(\mathrm{d})$ & Mill. $€$ & $\% \mathrm{~s} /(\mathrm{d})$ & Mill. $€$ & $\% \mathrm{~s} /(\mathrm{d})$ & Mill. $€$ & $\% \mathrm{~s} /(\mathrm{d})$ \\
\hline Resultados ordinarios & 196 & $4,70 \%$ & 59 & $6,00 \%$ & 4 & $3,00 \%$ & 56 & $6,40 \%$ \\
\hline Result. extraordinarios & 33 & $0,80 \%$ & 8 & $0,80 \%$ & 0 & $0,20 \%$ & 8 & $0,90 \%$ \\
\hline Impuesto de Sociedades & 51 & $1,20 \%$ & 7 & $0,80 \%$ & 2 & $1,80 \%$ & 5 & $0,60 \%$ \\
\hline Resultado del ejercicio (b) & 178 & $4,30 \%$ & 60 & $6,10 \%$ & 2 & $1,40 \%$ & 59 & $6,80 \%$ \\
\hline Cash-Flow & 476 & $11,40 \%$ & 109 & $11,00 \%$ & 8 & $6,20 \%$ & 101 & $11,70 \%$ \\
\hline Valor Añadido & 1.693 & $40,60 \%$ & 283 & $28,60 \%$ & 33 & $26,40 \%$ & 251 & $29,00 \%$ \\
\hline $\begin{array}{l}\text { RENTABILIDAD ECONÓMICA }((\mathrm{b}+\mathrm{c}) / \\
\text { Act.) }\end{array}$ & & $4,70 \%$ & & $5,70 \%$ & & $1,90 \%$ & & $6,20 \%$ \\
\hline rotación (d/Activo) & & $74,60 \%$ & & $77,40 \%$ & & $86,90 \%$ & & $76,20 \%$ \\
\hline margen $((b+c) / d)$ & & $6,30 \%$ & & $7,40 \%$ & & $2,20 \%$ & & $8,20 \%$ \\
\hline $\begin{array}{l}\text { RENTABILIDAD FINANCIERA (b/ } \\
\text { Neto) }\end{array}$ & & $7,90 \%$ & & $9,90 \%$ & & $2,50 \%$ & & $10,80 \%$ \\
\hline Facturación por empleado & 0,144 & & 0,247 & & 0,202 & & 0,255 & \\
\hline Valor Añadido / empleado & 0,059 & & 0,071 & & 0,053 & & 0,074 & \\
\hline Cash-Flow por empleado & 0,016 & & 0,027 & & 0,013 & & 0,03 & \\
\hline
\end{tabular}

(a) Conjunto empresas CNAE 2640 (unas 400 empresas, con cuentas registradas no consolidadas;

Fuente: SABI. Elaboración propia. 
más de cien empleados y del resto del sector, con datos también del año 2005. Las empresas mayores, al margen de haber obtenido un mejor año en resultados, facturación y cashflow por empleado, tienen gastos más intensos en materiales y más reducidos en gastos de personal respecto a las PYME. No aparecen diferencias entre los restantes gastos de explotación (gas, electricidad, etc.). Mayores precisiones sobre la rentabilidad y los costes en la industria se desarrollarán a continuación.

\subsection{Evolución de la inversión y la rentabilidad}

En este análisis se ha efectuado un seguimiento desde 1993 hasta 2005 sobre las cuentas empresariales para analizar la evolución de rentabilidad de estas sociedades. En primer lugar se ha estudiado la denominada Inversión Neta -para el agregado sectorial-, definida como la diferencia interanual del valor de los activos reflejado en las cuentas sociales de las empresas.

En se reflejan gráficamente dos variables, la Inversión Neta anual (con datos corregidos de la depreciación monetaria, equiparados a euros de 2005) y el cociente entre ésta y el activo del año previo. Además, se han trazado unas líneas de tendencia orientativas. El sector ha venido aplicando niveles de inversión muy elevados (Fig. 2). Se confirma que, en los últimos doce años, con grandes oscilaciones anuales, se vienen manteniendo volúmenes promedio de inversión neta en torno a 90-100 millones de euros por año (con una ligera tendencia decreciente), si bien su peso respecto del activo total ha ido reduciéndose desde niveles próximos al 37\% (1994) hasta cifras del 10\% e inferiores, a partir del 2001 (promedio del 7\% durante los últimos cinco años). Y esto puede ser un aspecto preocupante en un sector que ostenta el liderazgo tecnológico a nivel mundial.

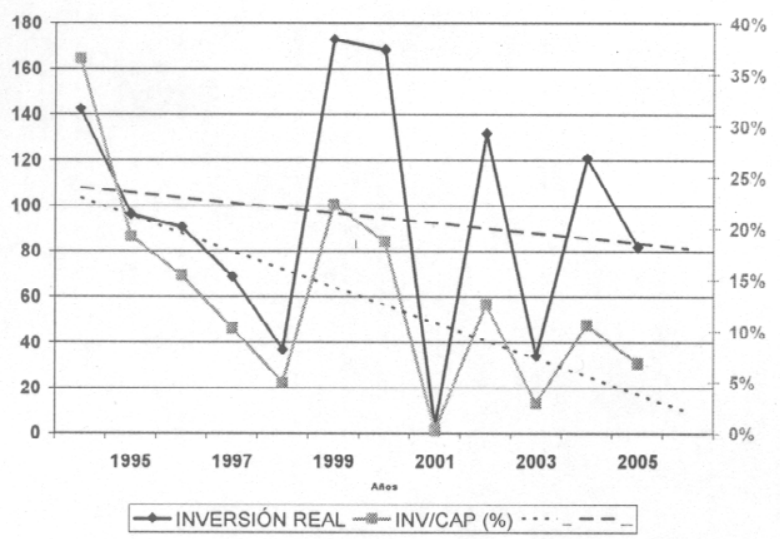

Fig. 2- Evolución de la Inversión Neta (Millones de €-2005) y de la Ratio Inversión/ Activo (\%). 1994-2005. Industria de Fritas, Colores y Esmaltes Cerámicos. Fuente: SABI. Elaboración propia.

La Fig. 3 muestra la relación entre los aumentos de fondos, propios y ajenos, interanuales invertidos, que informan sobre cómo se han venido financiando las nuevas inversiones durante la última década, desde 1995 hasta 2004. En función de la coyuntura económica se ha recurrido más a los fondos propios (1997-99) o a los fondos ajenos (1994-96; 2000-2003). Hacia finales de la década de los 90 se hizo un esfuerzo intenso de autofinanciación, si bien, posteriormente, la tendencia cambió en el sentido de incrementar el endeudamiento siguiendo la lógica impuesta por los bajos tipos de interés y también por las limitaciones del volumen de los fondos propios frente a las grandes necesidades de recursos requeridos para financiar la expansión de la industria.

No obstante y a la vista de la evolución de la facturación de la industria (Fig. 4) siguiendo una tendencia lineal, no

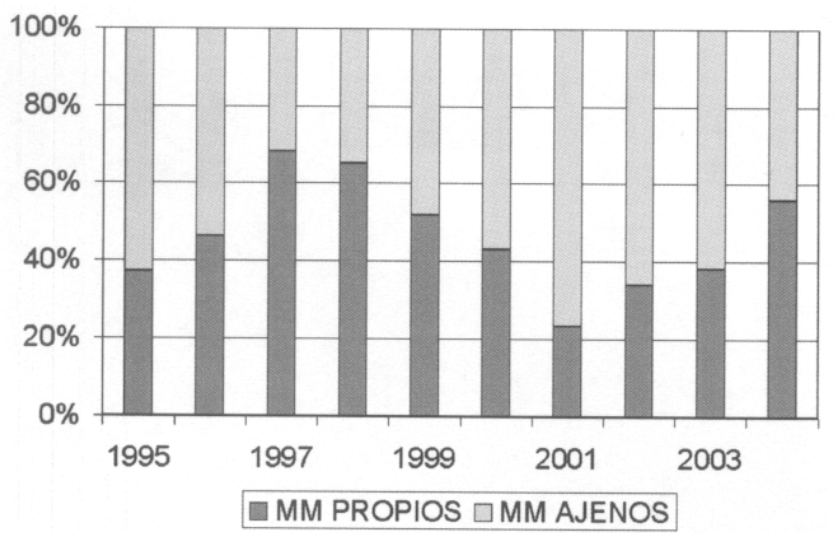

Fig. 3- Evolución del Endeudamiento y la Autofinanciación. Industria de Fritas, Colores y Esmaltes Cerámicos.

Notas: Medias Móviles centradas tres años. Capitales en Miles de Euros. Fuente: SABI. Elaboración propia.

parece presentar problemas proseguir con autofinanciación en los porcentajes antes vistos. Ahora bien, la evolución aparece ligeramente diferente si se expresa la facturación en unidades monetarias constantes (del año 1993), como también se refleja en el gráfico mencionado. Si no son los volúmenes, quizá sean los precios de venta los que últimamente reflejen un estancamiento.

Se observa pues, una estabilización de los ingresos reales a partir sobre todo del año 2002, circunstancia compartida por el empleo del sector, estancado en torno a los 4 mil empleados.

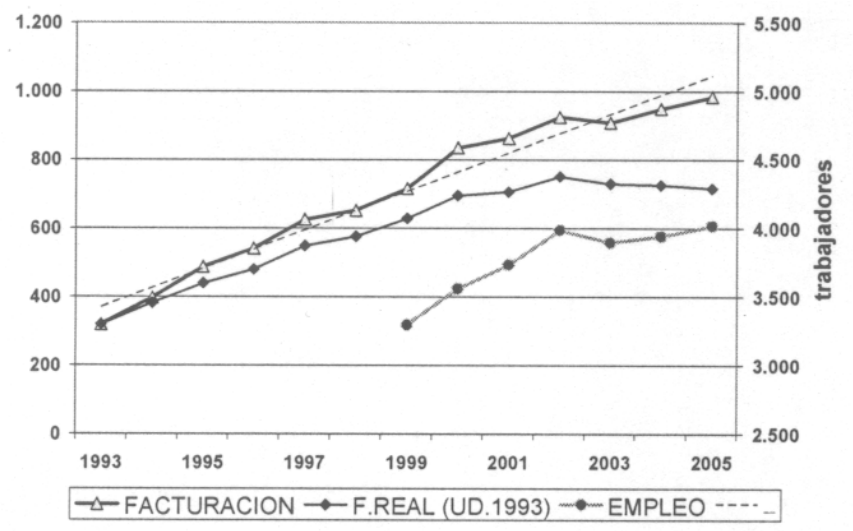

Fig. 4- Evolución de la facturación Millones de €) y del empleo. Industria de fritas, esmaltes y colores cerámicos. Fuente: SABI. Elaboración propia.

Finalmente, se analiza la evolución temporal de las rentabilidades del capital en la industria esmaltera (Fig. 5). La rentabilidad se compara con los tipos de interés preferenciales aplicados a las empresas por los bancos (según datos del Banco de España). Se observa cómo los fondos propios se remuneran entre 9 -12 puntos más que el indicador de referencia, pero esta 
diferencia se ha reducido intensamente a partir de 2000, hasta niveles de 5-8 puntos. La rentabilidad económica, aplicada al conjunto del capital, ha evolucionado próxima al indicador de referencia, distanciándose sólo entre 1 y 5 puntos por encima.

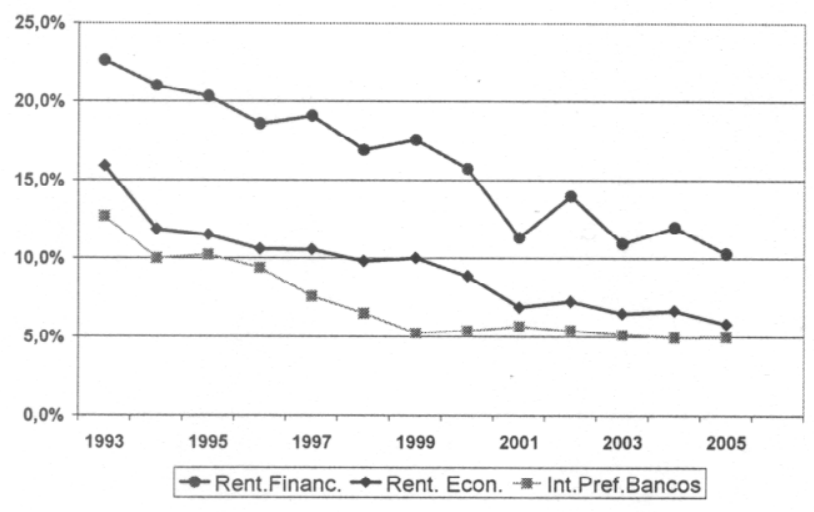

Fig. 5- Evolución de la Rentabilidad (1993-2005). Industria de Fritas, Esmaltes y Colores Cerámicos. Fuente: SABI. Banco de España. Elaboración propia.

Anteriormente, (13) se estimó que el sector perdió rentabilidad en la década de los 90, pasando del 32\% en 1990 al $15 \%$ en el 2000. Estas mismas pérdidas de productividad y de rentabilidad en la industria es recogida por otros autores (19). Se confirma, pues, la tendencia, y ello es altamente preocupante porque puede afectar a las estrategias de I+D e innovación de estas empresas, según (22). Para otros autores la reducción de precios y márgenes en el sector es una consecuencia de la mayor competencia, motivada por la aparición de nuevos agentes y las fuertes inversiones industriales (9), criterios que coinciden con los datos expresados en el presente trabajo.

Se ha comprobado, efectivamente, que en el periodo analizado, los ingresos han crecido casi dos puntos porcentuales por debajo de los gastos. Estos han evolucionado entre el 10\% y el 13\%, según tipos y a excepción de los gastos financieros que su crecimiento ha sido reducido ( $1 \%$ anual).

No obstante, la composición de los gastos de explotación (vistos en la Tabla XII para 2005) no ha variado con notoriedad. Los bienios 2004-05 y 1994-95, aportan promedios en los que las diferencias más notables en la estructura de gastos se dan con los gastos del capital (la depreciación, que aumenta casi un punto -del $4,4 \%$ al 5,3\%-, y los gastos financieros que reducen su cuota en esa misma cantidad -del 2,4\% al 1,5\%). La participación de los gastos de personal no se altera (en torno al $16 \%$ ), pero si la de las materias primas, que desciende su cuota un punto (del 59,2\% al 58,1\%), lo mismo que asciende los otros gastos de explotación, pasando de $17,7 \%$ al $18,7 \%$. Estos datos no reflejan o no recogen la importante subida de precios habida en ciertas materias primas (óxido de zinc) y en el gas natural (comentados con anterioridad).

Sin embargo, en 2005 los resultados de explotación, siguiendo la tendencia de años anteriores, se han reducido fuertemente, en general, por la ralentización de los ingresos. A pesar de lo cual, los resultados del ejercicio 2005 se han reducido menos respecto al 2004 (un 8\%), por el apoyo ocasional aportado por los beneficios de tipo extraordinario y por la reducción del impuesto de sociedades (gracias a la aplicación contable del crédito fiscal que permite anticipar futuros ahorros de impuestos).

\subsection{El reto medioambiental.}

Con una gran adaptabilidad ante los cambios, la industria está sabiendo dar respuesta a los retos que plantea una legislación medioambiental cada vez más rigurosa, por la creciente demanda social de establecer pautas de producción y consumo más sostenibles.

Los principales instrumentos legales de carácter horizontal que afectan a la industria en general, y la esmaltera en particular, son:

Directiva 96/61/ EC sobre control y prevención integrados de la contaminación (Directiva IPPC, Integrated Pollution Prevention and Control).

Directiva 2003/87/ EC que establece las bases para permitir el comercio de emisiones de gases de efecto invernadero en el interior de la Comunidad.

Propuesta de regulación relativa al Registro, Evaluación, Autorización y Restricción (REACH) de productos químicos y establecimiento de la Agencia Europea de Productos Químicos.

La incidencia ambiental potencial de la producción de fritas se debe en gran medida a que se trata de un proceso intensivo en el uso de la energía, con empleo de altas temperaturas, lo que da lugar a elevadas emisiones de productos de la combustión -no solo gases efecto invernadero (CO2, SOx)- sino también de emisiones de metales pesados -utilizados en la pigmentación y opacificación del esmalte- y las provenientes de la oxidación del nitrógeno atmosférico. Existen soluciones técnicas capaces de reducir las emisiones contaminantes, pero llevan asociadas implicaciones, severas a veces, en el aspecto económico-financiero. No obstante, la industria ha aceptado un compromiso para la utilización de técnicas y la implantación de mejoras correctoras para mejorar el impacto ambiental de su fabricación.

En lo que respecta al programa $\mathrm{REACH}$, su aplicación al mundo de la cerámica y fritas, en la medida del uso extensivo, como materias primas, de una amplia variedad de productos químicos, incidiría en un elevado número de controles, cuando en realidad su uso implica una peligrosidad bastante limitada. Por otro lado, la catalogación de sus productos como peligrosos no parece procedente, al menos para el conjunto de la producción. En todo caso, se trata de una valoración todavía por establecer. La posición sustentada en las comisiones medioambientales de la UE por las asociaciones ANFECC y ASCER, y las correspondientes italianas, en defensa de los intereses del sector, previsiblemente permitirá perfilar la incidencia final del programa REACH. Posiblemente, el REACH llegue a incidir en diferente forma sobre los productos pudiendo afectar en mayor medida a ciertos colores cerámicos $y$, en mucha menor medida, a las fritas $(23,24)$.

La incidencia de la regulación sobre los derechos de emisión y del comercio de emisiones de $\mathrm{CO}_{2}$, previstos a efectos de conseguir los objetivos del Protocolo de Kyoto, previsiblemente tendrá un efecto negativo sobre el sector. Se han asignado derechos de emisión que limitarán el desarrollo de la industria en España a medio plazo, al tiempo que, con ello, se refuerzan las opciones de implantación exterior en zonas sin las restricciones contempladas. No obstante, la última asignación parece haber sido aceptada como razonable por el sector.

En relación con la Directiva IPPC, se han publicado normas legales de ámbito nacional (Ley 16/2002) y autonómico (Ley 2/2006 y Decreto 127/06 de la Generalitat Valenciana) para 
dar aplicación a las previsiones de la normativa comunitaria, donde se contempla que grupos técnicos sectoriales elaboren sus respectivos documentos BREF. El documento BREF recoge, entre otros aspectos relevantes, primero, una descripción de las mejores técnicas disponibles (BAT, best available techniques) de aplicación en las actividades productivas más representativas y contaminantes de cada sector; asimismo, el BREF recoge los valores límites de emisiones contaminantes asociados a dichas técnicas. En ellos, se recomienda implantar instalaciones y controles con los que se pueden alcanzar mejoras notables, tales como reducir las emisiones contaminantes a la atmósfera, gestionar correctamente las emisiones de aguas residuales $\mathrm{y}$ de residuos, mitigar los niveles de ruidos y vibraciones $\mathrm{y}$ reducir los consumos de materias primas y de energía.

La ley prevé que las empresas tengan que solicitar la Autorización Ambiental Integrada, para todas las instalaciones afectadas, que deben conseguir antes de la fecha límite de 31/10/2007. En la CV existen en torno a 500 empresas afectadas de todos los sectores, de las que prácticamente la mitad pertenece a la cadena cerámica; otra rama de actividad importante es la industria agroalimentaria.

El BREF de vidrio-fritas (categoría-epígrafe IPPC 3.3) fue concluido y publicado en 2001 por la Comisión Europea. Las instalaciones afectadas son las que procesan más de 20 toneladas/día, implicando a unas 23 empresas de esmaltes en la CV. El BREF es de aplicación a nivel europeo, ámbito donde alcanza a afectar a unas sesenta empresas (en Italia, a unas 32). Se han elaborado también otros documentos BREFs relativos a la cadena cerámica, como los de productos cerámicos (categoría 3.5), pigmentos cerámicos (categoría 4.2) e incluso para las atomizadoras (categoría 2.7), amén de otros BREFs de tipo horizontal, como por ejemplo, para transporte y manipulación de materiales a granel no peligrosos.

Las principales emisiones en la industria de fritas son las siguientes, según actividades desarrolladas (25): a) En recepción de materias primas, molienda, dosificación y mezclas: Polvo y partículas, $\mathrm{SiO} 2$ cristalino; b) En proceso de fusión: Polvo y partículas, $\mathrm{CO}, \mathrm{NOx}, \mathrm{SOx}, \mathrm{HF}, \mathrm{HCl}$, compuestos de boro y metales pesados; c) En conformado y operaciones posteriores: Polvo y partículas, aguas residuales.

La Autorización Ambiental Integrada exige, siguiendo las pautas del documento BREF, una adecuación de las instalaciones y el control de emisiones que no deben superar los niveles dispuestos en unas tablas de máximos, para los contaminantes arriba contemplados. Las instalaciones más afectadas y necesitadas de adecuación, se referían a:

1) El control de los gases de de combustión en hornos, sobre todo sus emisiones ácidas: se recomienda la canalización de humos por medio de sistemas con filtros de mangas, con aplicación de reactivos para neutralizar dichas emisiones.

2) El control de emisiones difusas en instalaciones $y$ equipos de almacenamiento y transporte: se recomienda el uso de silos o el cierre absoluto de tolvas y cintas, el cerramiento completo (o al menos el cierre de fondo, laterales y techo), con firme asfaltado, de almacenes. Se requiere, asimismo, instalaciones para el lavado de vehículos de transporte.

Menores requerimientos han necesitado el tratamiento y control de aguas residuales y de residuos sólidos, para los que en buena parte está previsto su reutilización. En la industria castellonense, la adaptación de las esmalteras a la problemática medioambiental va muy avanzada, habiéndose cubierto el $95 \%$ de las inversiones previstas que ascendían a unos 30 millones de euros.

\section{LAS FRITAS EN EL SISTEMA SECTORIAL DE INNOVACIÓN CERÁMICO.}

\subsection{Introducción.}

La industria de esmaltes, por su actividad innovadora, forma parte, pues, del Sistema Sectorial de Innovación Cerámico (7). Su contribución, decisiva para el desarrollo de la cerámica, ha venido dada por el intenso esfuerzo innovador, tanto en el campo de la generación de tecnología como en la difusión de la misma entre los ceramistas (3), ya que los fabricantes de esmaltes no sólo proveen de esmaltes a las empresas cerámicas sino que, además, proporcionan asistencia técnica, tecnología y diseño, procurando un mayor valor añadido a sus clientes.

En la Fig. 6 se representa esquemáticamente el SIVSEC, con los participantes del sector, dentro de su entorno correspondiente, según el modelo desarrollado en los trabajos sobre el Sistema Valenciano de Innovación $(26,27)$.

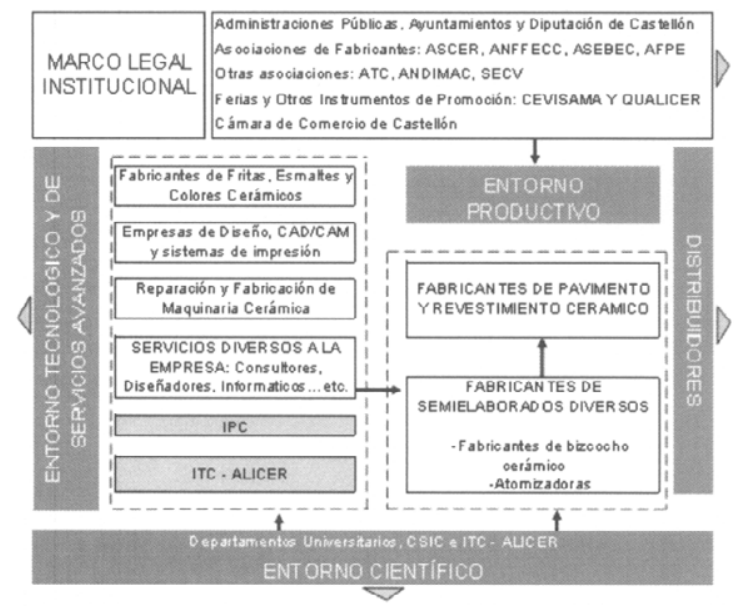

Fig. 6- Sistema sectorial de innovación cerámico de Castellón. Fuente: Gabaldón 2008.

El entorno productivo recoge al conjunto de fabricantes, no sólo los de pavimentos y revestimientos cerámicos sino también los de piezas especiales y los de semielaborados diversos entre los que encontramos: los fabricantes de bizcocho cerámico y las atomizadoras. Las empresas cerámicas de Castellón constituyen un conjunto de PYME dinámicas y flexibles, con escasa especialización y poco dadas a colaborar entre ellas en proyectos conjuntos.

El entorno tecnológico y de servicios avanzados del SIVSEC engloba toda institución capaz de ofrecer y transmitir conocimientos tecnológicos transformables en innovación, como maquinaria, nuevos materiales, asesoramientos y servicios tecnológicamente nuevos. Es importante señalar que los elementos de este entorno son nexo de unión entre las necesidades del entorno productivo y las capacidades potenciales del entorno científico. Como muestra la figura anterior, se trata de proveedores que ofrecen soluciones tecnológicas novedosas o mejoradas y las difunden en el sector: proveedores de fritas, esmaltes y colores, de maquinaria y de servicios varios (diseño, CAD/CAM, serigrafía, etc.). Como se ha constatado en estudios anteriores (7), en este sector los proveedores son el agente que más se utiliza en la cooperación para la innovación. En concreto, los fabricantes de esmaltes españoles, como se ha expresado, no sólo proporcionan los esmaltes sino que, además, proporcionan asistencia técnica, tecnología y diseño, para facilitar un mayor valor añadido a 
sus clientes. Por su parte, los fabricantes de maquinaria para la industria cerámica ofrecen no sólo la maquinaria (los grandes fabricantes son italianos), sino también el asesoramiento y la asistencia técnica postventa. Pertenecen a este entorno, las empresas de diseño, informatización y nuevas tecnologías, consultoría tecnológica, etc. Algunos de los ceramistas, el $18 \%$ según el estudio de (28), tienen departamento interno de diseño, pero la mayoría compra los diseños a gabinetes técnicos, o bien se los proporcionan, como ya se ha señalado, los fabricantes de fritas y de piezas especiales. Dentro del entorno tecnológico, cabe incluir al Instituto de Tecnología Cerámica (ITC), al que nos referiremos más detalle más adelante, y al Instituto de Promoción Cerámica (IPC), entidad dependiente de la Diputación de Castellón que está especializada en las cerámicas de aplicación arquitectónica en campos muy diversos.

Por su parte, el entorno científico se compone esencialmente delosgrupos investigadores delas Universidadesy Organismos Públicos o Privados de Investigación. En concreto, en el SIVSEC destacan, como se analiza en detalle más adelante, la Universitat Jaume I de Castellón y el Instituto de Tecnología Cerámica (ITC). Es allí dónde diversos departamentos, particularmente los departamentos de Ingeniería Química y Química Inorgánica y Orgánica, desarrollan líneas de investigación de interés para el sector en el campo de la tecnología cerámica, la química, la contaminación ambiental, el diseño cerámico, entre otros. Concretamente, el ITC ha estudiado los aspectos teóricos y empíricos de amplias fases del proceso de producción cerámico, así como lo relativo a las materias primas y los productos intermedios, entre los que se encuentran las fritas y los colores cerámicos, que forman los engobes y esmaltes (29). En la Universidad Politécnica de Valencia, el Centro de Investigación en Tecnologías Gráficas investiga sobre el control y sistematización de las líneas de esmaltado con la finalidad de reducir la utilización de esmaltes, aumentar la calidad del producto final y evitar la producción obtenida con tonos indeseados. En dicha universidad existen igualmente grupos de investigación ligados a proyectos de economía de la empresa, organización de la producción, marketing, logística etc. Así mismo, el Instituto de Cerámica y Vidrio, perteneciente al Consejo Superior de Investigaciones Científicas (CSIC), lleva a cabo investigaciones básicas y aplicadas en diferentes campos relacionados con la cerámica y el vidrio que han sido de considerable valor para el subsector de esmaltes, tanto enfocadas a las innovaciones de proceso (hornos), como de producto y diversificación de la producción.

Por último, el entorno institucional tiene una función primordial de apoyo: lo constituyen: 1) las distintas Administraciones Públicas que, al desarrollar sus políticas, pueden influir de forma más o menos intensa en la actividad industrial; 2) el conjunto de asociaciones de soporte (Asociación Española de Fabricantes de Azulejos y Pavimentos Cerámicos, ASCER; Asociación Nacional de Fritas, Esmaltes y Colores Cerámicos, ANFFECC; Asociación de Fabricantes de maquinaria y bienes de equipo para la Industria Cerámica, ASEBEC; Asociación Española de Técnicos Cerámicos, ATC; Asociación Nacional de Distribuidores Cerámicos y Materiales de Construcción, ANDIMAC; Asociación de Fabricantes de Piezas Especiales, AFPE; Sociedad Española de Cerámica y Vidrio, SECV, creadora de los Premios Alfa de Oro a la innovación científica y tecnológica, que se conceden desde 1982 en el marco de CEVISAMA ) y constituyen agentes de gran importancia para el sector. La revista de la SECV Boletín de la SECV, única revista españoa incluída en el campo cerámicoa en el Scientific Citation Index, ejerce una notable influencia como elemento de conexión entre la investigación en cerámicas avanzadas y su traslación al entorno productivo cerámico; 3) las Ferias y Congresos (Feria Valenciana de la Cerámica, CEVISAMA y Congreso Internacional Cerámico en Castellón, QUALICER) como instrumentos de promoción e importantes fuentes de información para la innovación tecnológica, y por último, 4) otros, como la Cámara de Comercio de Castellón, el Colegio de Ingenieros Industriales y la Confederación de Empresarios de Castellón, como organismos de apoyo y prestación de servicios a empresarios que debido a la relevancia del sector cerámico en la economía local, tienen un papel más significativo que en otros sectores.

Conviene resaltar el papel de la Asociación Española de Técnicos Cerámicos (ATC).Secreoen 1976 conlaidea deagrupar, en un mismo colectivo, a los técnicos de la industria cerámica. Fue resultado de las inquietudes de un grupo de profesionales que comprendieron la necesidad de crear un vehículo que sirviese para divulgar los conocimientos científicos y técnicos. En la actualidad cuenta, aproximadamente, con unos 650 profesionales y 140 empresas asociadas, que pertenecen a los sectores productores de baldosas cerámicas, esmaltes y fritas, maquinaria y bienes de equipo, $y$, por supuesto, todo tipo de industrias auxiliares. En definitiva, la masa social de la ATC viene a significar el $80 \%$ de los profesionales que trabajan en el sector cerámico. La ATC organiza actividades destinadas a potenciar la formación e información del técnico a través de conferencias, jornadas divulgativas, mesas redondas, cursos y, de manera especial, mediante el Congreso Internacional del Técnico Cerámico que se celebra los años impares. Se mantiene así la dinámica y comunicación entre los distintos profesionales que forman parte del SIVSEC y se mejora su articulación. De hecho no se conoce actualmente la existencia de una similar en otros sectores tradicionales de la Comunidad Valenciana. La asociación edita bimensualmente una revista llamada "InformATC".

En cuanto a las políticas de las Administraciones, ya se han expresado las correspondientes a la regulación medioambiental que, a instancia de la UE, se han reflejado en leyes y reglamentos nacionales y autonómicos. Aparte de las políticas genéricas para la industria, conviene resaltar el Plan de Competitividad del Sector de la Cerámica, desarrollado a nivel autonómico. que incluye cuatro apartados con acciones dirigidas al sector de esmaltes: 1) el fomento de la actividad de $\mathrm{I}+\mathrm{D}+\mathrm{i} ; 2)$ apoyo a la realización de campañas de comunicación; 3) estudio de la situación del subsector desde el punto de vista de la Directiva 96/61 / UE (IPPC); 4) caracterizar y clasificar los productos del sector (iniciativa REACH).

Hay que destacar también la apertura o internacionalización del SIVSEC, consecuencia del subsector de fritas, esmaltes y colores que exporta más de la mitad de su producción, y el carácter exportador de la producción española de baldosas, una dependencia tecnológica de Italia en cuanto a bienes de equipo así como una estrecha relación entre el ITC y otras instituciones extranjeras de I+D, como el Instituto Cerámico de Bolonia y, en fin, las relaciones entre las asociaciones de empresarios de Castellón y de Emilia Romagna, tales como las existentes entre ASCER y ANFFECC, con Confindustria Cerámica (anteriormente denominada Assopriastrelle) y Ceramicolor, sus homónimas italianas. 


\subsection{Características de la innovación tecnológica}

Para este apartado se ha utilizado una explotación ad hoc de la Encuesta sobre Innovación Tecnológica de las Empresas del Instituto Nacional de Estadística para el año 2004. Concretamente, se dispone de información agregada de trece de las empresas de fritas y esmaltes más importantes del subsector que suponen, en conjunto, el ochenta por ciento de su facturación y el setenta y cinco por ciento de sus empleados.

Al comparar la intensidad de innovación (Gastos en actividades Innovadoras/Cifra de negocios x100) de las empresas con actividades de $\mathrm{I}+\mathrm{D}$, tanto de las empresas de fritas $\left(1^{\prime} 87\right)$ con el conjunto del sector químico, (1'74) y el total de la industria de la Comunidad Valenciana (1'98), nos encontramos con que el esfuerzo realizado es mayor para el conjunto de la industria que para el sector químico y las empresas de fritas. No obstante, un análisis más detallado, ver Tablas XIII y XIV, permite observar diferencias importantes en cuanto a la composición del gasto.

En primer lugar, destaca la preeminencia de la I+D interna de las empresas de fritas $\left(79^{\prime} 7 \%\right)$, muy superior a la del conjunto del sector químico $\left(58^{\prime} 5 \%\right)$ y al total de la industria de la Comunidad Valenciana (27'9\%). De hecho, el gasto en I+D interna de las empresas de la muestra representa el $466^{\prime} 7 \%$ del realizado por el sector químico de la Comunidad Valenciana, y el 9'5 del conjunto relativo a la industria valenciana. Si se toma en consideración que las empresas de fritas representan el 11\% de la cifra de negocio del sector químico de la Comunidad Valenciana y el 15'2\% de sus trabajadores, la proporción del gasto en $\mathrm{I}+\mathrm{D}$ realizada por las empresas de la muestra es más de cuatro veces superior a la que cabría esperar por sus ingresos.

Por su parte, la adquisición de I+D externa es, en términos relativos, menor para el sector químico $\left(5^{\prime} 6 \%\right)$ que para las empresas de fritas $\left(6^{\prime} 9\right)$ y mucho menor que para el conjunto de la industria $\left(18^{\prime} 2 \%\right)$. Así, el gasto en I+D externa de las empresas de fritas representa el 1'3 del de la industria valenciana, pero es el $42^{\prime} 3 \%$ del realizado por el sector químico, cifra esta última de nuevo considerable.

En cuanto a la adquisición de maquinaria y equipos, la encuesta indica su escaso peso para las empresas de fritas $\left(3^{\prime} 9 \%\right)$ tanto frente al sector químico $\left(24^{\prime} 5 \%\right)$ como ante la industria en su conjunto $\left(38^{\prime} 3 \%\right)$. Precisamente, la adquisición de maquinaria y equipos de las empresas de fritas representa tan sólo el 5'5\% del realizado por el sector químico (la mitad de lo que representan de acuerdo a sus ingresos), y el 0 '3 del valor correspondiente de la industria valenciana.

En cuanto a la adquisición de otros conocimientos externos, la formación, la introducción de innovaciones en el mercado $\mathrm{u}$ otros preparativos para producción y/o distribución, en su conjunto, las empresas de fritas dedican menos esfuerzo económico $\left(9^{\prime} 5 \%\right)$ que los grupos de referencia analizados ( $11^{\prime} 5$ y $15^{\prime} 5 \%$, industria química y total industria, respectivamente) si bien la diferencia no es tan relevante.

La distribución de los gastos de las actividades a través de los cuales innovan las empresas de esmaltes, pone en evidencia que la innovación se lleva a cabo por las empresas a través de sus propias capacidades, con escasa participación externa. La mayor diferencia con la innovación desarrollada por los otros sectores es el bajo gasto en adquisición de maquinaria y equipos, lo que indica que las empresas buscan, principalmente,

TABLA XIII: COMPOSICIÓN DE LOS GASTOS DE INNOVACIÓN DE LAS EMPRESAS DE FRITAS EN COMPARACIÓN CON EL SECTOR QUÍMICO Y TOTAL DE LA INDUSTRIA DE LA COMUNIDAD VALENCIANA. AÑO 2004.

\begin{tabular}{|c|c|c|c|c|c|c|}
\hline & \multicolumn{2}{|c|}{ Empresas de Fritas } & \multicolumn{2}{|c|}{ Sector Químico CV } & \multicolumn{2}{|c|}{ Total Industria CV } \\
\hline & miles de $€$ & $\%$ & miles de $€$ & $\%$ & miles de $€$ & $\%$ \\
\hline $\mathrm{I}+\mathrm{D}$ interna & 11.830 & 79,7 & 25.359 & 58,5 & 124.599 & 27,9 \\
\hline Adquisición de I+D (I+D externa) & 1.024 & 6,9 & 2.423 & 5,6 & 81.326 & 18,2 \\
\hline Adquisición de maquinaria, equipos & 580 & 3,9 & 10.603 & 24,5 & 170.860 & 38,3 \\
\hline Resto (a) & 1.410 & 9,5 & 4.963 & 11,5 & 69.325 & 15,5 \\
\hline $\begin{array}{l}\text { Gastos totales en actividades innovadoras en } \\
2004 \text { (miles de } € \text { ) }\end{array}$ & 14.846 & 100 & 43.348 & 100 & 446.110 & 100 \\
\hline
\end{tabular}

(a): Adquisición de otros conocimientos externos, Formación, Introducción de innovaciones en el mercado u Otros preparativos para producción y/o distribución. Fuente: (30) Explotación ad hoc y elaboración propia.

TABLA XIV: PARTICIPACIÓN DE LAS EMPRESAS DE LA MUESTRA EN LOS GASTOS DE INNOVACIÓN DEL SECTOR QUÍMICO Y DEL CONJUNTO DE LA INDUSTRIA DE LA COMUNIDAD VALENCIANA. DATOS RELATIVOS. AÑO 2004.

\begin{tabular}{|l|r|r|}
\hline & \multicolumn{2}{|c|}{ Empresas de Fritas sobre } \\
\hline & $\begin{array}{c}\text { Industria Química } \\
\text { CV }\end{array}$ & $\begin{array}{c}\text { Total industria } \\
\text { CV }\end{array}$ \\
\hline I+D interna & 46,7 & 9,5 \\
\hline Adquisición de I+D (I+D externa) & 42,3 & 1,3 \\
\hline Adquisición de maquinaria, equipos & 5,5 & 0,3 \\
\hline Resto(a) & 28,4 & 2,0 \\
\hline $\begin{array}{l}\text { Gastos totales en actividades } \\
\text { innovadoras en 2004 }\end{array}$ & 34,3 & 3,3 \\
\hline
\end{tabular}

(a): Adquisición de otros conocimientos externos, Formación, Introducción de innovaciones en el mercado u Otros preparativos para producción y/o distribución.

Fuente: (30) Explotación ad hoc y elaboración propia. innovaciones de producto, y que las innovaciones de proceso son innovaciones incrementales. En este sentido, la encuesta revela la valoración que realizan las empresas sobre los efectos de su actividad innovadora. Actividad que, según las empresas de fritas, repercute en los productos $(69 \%)$ en mayor medida que en los procesos $(46 \%)$. Por último, la repercusión sobre otros efectos (i.e. cumplimiento de los requisitos normativos, reducción del impacto medioambiental o mejora en la salud y la seguridad) es también menor (46\%). En la misma línea, si bien con menores diferencias entre categorías, se sitúan los datos del sector químico $(56 \%, 45 \%$ y $51 \%$ respectivamente).

La encuesta identifica a nueve empresas, un $69 \%$ de las encuestadas, con actividades innovadoras en el periodo 2002-2004, cifra sensiblemente inferior al conjunto del sector químico valenciano (93\%). Siete de las nueve empresas pertenecen a un grupo más amplio. Así mismo, la encuesta señala que, a finales de 2004, ocho empresas (el 62\%) se 
encontraban con alguna actividad de innovación en curso o no exitosa, y cinco (el 39\%) habían abandonado alguna de sus actividades innovadoras. De las nueve empresas con actividades innovadoras, todas realizaron innovaciones de producto y ocho, además, innovaciones de proceso.

Por lo que respecta a las innovaciones de carácter organizativo, cabe indicar que algo más de la mitad, el 54\% de las empresas innovadoras, introdujeron cambios importantes en la organización del trabajo de la empresa (65\% para el sector químico).

En cuanto a la repercusión sobre la cifra de negocio de las innovaciones introducidas en los bienes y/o servicios ofertados por la empresa, la encuesta (ver Tabla XV) indica que representaron en torno a un $16 \%$ de la misma (en torno al 20\% para el sector químico): porcentaje que se eleva al 19\% para las empresas con innovaciones de producto (un 28\% para el sector químico). Se constata que el sector está en una fase madura y que no se producen innovaciones que modifiquen sustancialmente el volumen de negocio de los productos ofertados.

TABLA XV: INCIDENCIA ECONÓMICA DE LA INNOVACIÓN DE PRODUCTO. 2004

\begin{tabular}{|l|c|c|c|}
\hline $\begin{array}{l}\text { Porcentaje de la cifra de } \\
\text { negocios de 2004 debida a: }\end{array}$ & $\begin{array}{l}\text { Del conjunto } \\
\text { de empresas } \\
\text { innovadoras }\end{array}$ & $\begin{array}{c}\text { Empresas } \\
\text { EIN }\end{array}$ & $\begin{array}{c}\text { Empresas con } \\
\text { innovación de } \\
\text { producto }\end{array}$ \\
\hline $\begin{array}{l}\text { Bienes y/o servicios que } \\
\text { fueron novedad únicamente } \\
\text { para la empresa }\end{array}$ & 8,6 & 8,9 & 10,5 \\
\hline $\begin{array}{l}\text { Bienes y/o servicios que } \\
\text { fueron novedad en el } \\
\text { mercado }\end{array}$ & 7,3 & 7,5 & 8,9 \\
\hline $\begin{array}{l}\text { Bienes y/o servicios que se } \\
\text { mantuvieron sin cambios }\end{array}$ & 84,1 & 83,6 & 80,7 \\
\hline
\end{tabular}

Fuente: (30) Explotación ad hoc y elaboración propia.

Respecto a la cooperación, la encuesta indica que el $61 \%$ del total de las empresas innovadoras cooperaron en innovación durante el periodo 2002-2004, lo que contrasta con el $80 \%$ para el conjunto de las empresas del sector químico. Más concretamente, la encuesta muestra una importancia similar para las tres modalidades de cooperación que se distinguen, no resaltando ninguna de ellas. La cooperación es baja para este tipo de empresas, lo que es corroborado por el hecho de que las fuentes de información más valoradas por las empresas de fritas son las internas a la empresa (69\%), porcentaje elevado respecto al conjunto del sector químico (52\%). Tras éstas se sitúan las procedentes del mercado $(39 \%)$, cifra sensiblemente inferior a la del conjunto del sector químico (59\%), categoría que incluye clientes, proveedores, consultores y competidores u otras empresas de la misma rama. La baja cooperación entre empresas hunde sus raíces en una desconfianza que previene a las empresas de cooperar en condiciones normales. La ausencia de confianza reduce la cooperación de las empresas, y esta repercute negativamente en su capacidad de innovar dado que las previene de realizar investigaciones y otros tipos de colaboraciones conjuntas. Como se verá más adelante en el estudio, incluso la colaboración de las diferentes empresas con los diferentes agentes del entorno científico no sigue un patrón homogéneo, focalizándose la cooperación de ciertas empresas con determinados institutos o departamentos y no con otros. Evidenciando así dos estrategias diferentes, aquellas que están más implicadas en el distrito y que por tanto hacen uso de las instituciones próximas para investigar e innovar, frente aquellas que prefieren instituciones periféricas a fin de garantizar una mayor discreción en sus investigaciones. Sólo cuando la situación se percibe como dramática que se abre la posibilidad de que se organicen conjuntamente para hacer frente a esa especial situación (como el surgimiento de la patronal ANFFECC). A la reducción de la falta de cooperación y confianza, que contrasta con la colaboración entre técnicos que sí existe, han ayudado poco situaciones como la creación de ITACA por parte de investigadores del ITC.

En cuanto a la protección de las innovaciones, como muestra la tabla XVI, las empresas de fritas y esmaltes recurren en mayor medida al registro de marca, el $62 \%$, y a las patentes, el $54 \%$, superando a las empresas del sector químico ( $43 \%$ y $30 \%$ respectivamente) $y$, con mayor amplitud, a la industria valenciana en su conjunto.

TABLA XVI: EMPRESAS EIN, SOBRE EL TOTAL DE EMPRESAS ENCUESTADAS, QUE ACTÚAN SEGÚN SE INDICA. PERIODO 2002-2004

\begin{tabular}{|l|c|c|c|}
\hline Número de empresas EIN que: & Fritas & Química & Industria CV \\
\hline Han solicitado patentes & 53,8 & 29,6 & 22,9 \\
\hline $\begin{array}{l}\text { Han registrado algún dibujo o } \\
\text { modelo industrial }\end{array}$ & n.d. & 8,8 & 16,3 \\
\hline Han registrado alguna marca & 61,5 & 43,2 & 30,1 \\
\hline Han reclamado derechos de autor & 0 & 0,8 & 2,2 \\
\hline
\end{tabular}

Fuente: (30) Explotación ad hoc y elaboración propia.

En síntesis, los datos de la encuesta indican que las empresas de fritas innovan principalmente realizando I+D interna $\mathrm{y}$, en menor medida, adquiriendo conocimientos externos, maquinaria y equipos, por lo que no es de extrañar que sus principales fuentes de información para innovar sean las internas. Se observa además, que su actividad innovadora se encuentra sensiblemente por debajo de su grupo de referencia, la industria química, y se orienta, en mayor medida, a innovaciones de producto. Además su cooperación es baja, bastante menor que la de las empresas del sector químico. Estos datos en su conjunto vienen a corroborar que nos encontramos ante una industria basada en la ciencia pero con pautas de innovación de un sector maduro que ha intentado paliar su disminución de la actividad innovadora con un aumento de los servicios a los clientes.

\subsection{Protección de innovaciones. Patentes.}

La industria española de fritas, al igual que la industria cerámica, por lo general no ha recurrido a la patente como medio de protección de las innovaciones, en parte debido a la dificultad de defenderlas, prefiriendo otras formas de protección. No obstante en la última década se ha incrementado el recurso a este tipo de protección para evitar usurpaciones.

La siguiente tabla muestra los datos sobre patentes que solicitaron las empresas de Fritas y Esmaltes. Durante el periodo 1999 - 2003 (ambos inclusive) se solicitaron veintitrés patentes, de las cuales veinte fueron de ámbito nacional y nueve de ámbito internacional (ver Tabla XVII).

En cuanto a las empresas del sector que han registrado patentes destacan COLOROBBIA ESPAÑA S.A., con cinco patentes (véase Tabla XVIII). Le siguen, ESMALGLASS, S.A. y TORRECID S.A., con tres patentes pero cinco registros cada una, y FERRO SPAIN, S.A. y FRITTA S.L., también con tres patentes pero cuatro registros cada una; Esmaltes S.A. ha registrado también tres patentes. 
TABLA XVII: PATENTES, SEGÚN ÁMBITO. 1999-2003.

\begin{tabular}{|c|c|c|c|}
\hline & Nacional & Internacional & Total año \\
\hline 1999 & 1 & 2 & 3 \\
\hline 2000 & 8 & 2 & 10 \\
\hline 2001 & 4 & 2 & 6 \\
\hline 2002 & 3 & 2 & 5 \\
\hline 2003 & 4 & 1 & 5 \\
\hline Total tipo & 20 & 9 & 23 \\
\hline
\end{tabular}

Fuente: Oficina Española de Patentes y Marcas (OEPM). Elaboración propia.

TABLA XVIII: NÚMERO DE PATENTES SOLICITADAS POR EMPRESA. 1999-2003.

\begin{tabular}{|l|r|}
\hline \multicolumn{1}{|c|}{ Empresa } & \multicolumn{1}{|c|}{ Patentes } \\
\hline COLOROBBIA ESPAÑA, S.A. & 5 \\
\hline ESMALGLASS, S.A. & 3 \\
\hline TORRECID S.A. & 5 (3 diferentes) \\
\hline FERRO SPAIN, S.A. & 4 (3 diferentes) \\
\hline FRITTA, S.L. & 4 (3 diferentes) \\
\hline VIDRES, S.A. & 2 \\
\hline COLORIFICIO CERAMICO BONET, S.A. & 1 \\
\hline ESMALTES, S.A. & 1 \\
\hline ITACA S.A. & 1 \\
\hline POLVO CERAMICO, S.L. & 1 \\
\hline
\end{tabular}

Fuente: OEPM. Elaboración propia.

El grueso de las patentes (25 de 29, el 86\%) fueron demandadas por un único solicitante, lo que indica que han sido innovaciones desarrolladas internamente por la propia empresa. Además, existen tres patentes con dos solicitantes, y una más con cinco. En estas cuatro patentes con solicitantes múltiples ha participado FRITTA S.L., con alguna o varias de las empresas o instituto tecnológico que aparece en la siguiente tabla (concretamente las tres patentes con doble solicitante son FRITTA S.L. con ISOFOTON, S.A., y la de cinco solicitantes es

TABLA XIX: EMPRESAS DE OTROS SECTORES QUE HAN PATENTADO EN COLABORACIÓN CON LAS EMPRESAS DE FRITAS Y ESMALTES. 1999-2003.

\begin{tabular}{|l|r|}
\hline \multicolumn{1}{|c|}{ Empresa } & Patentes \\
\hline ISOFOTON, S.A. & 3 \\
\hline FUCHS LUBRICANTES, S.A. & 1 \\
\hline INSTITUTO DE TECNOLOGIA CERAMICA & 1 \\
\hline TALLERES FORO, S.A. & 1 \\
\hline TAULELL, S.A. & 1 \\
\hline
\end{tabular}

Fuente: OEPM. Elaboración propia.

FRITTA S.L. con el resto de entidades de la Tabla XIX).

Los datos sobre patentes para el periodo analizado evidencian una nula cooperación de las empresas esmalteras entre sí, y una limitada cooperación entre estas empresas y otros elementos del SIVSEC.

\subsection{Las relaciones con el Instituto de Tecnología} Cerámica.

El Instituto de Tecnología Cerámica (ITC) permite poner, con pocas trabas burocráticas, a disposición del sector cerámico todo el potencial de conocimientos de un instituto universitario $\mathrm{y}$, al mismo tiempo, obtener un conocimiento rápido y directo de las necesidades presentes y futuras de un sector tan dinámico.

ComoCIT actúa comoorganismo deinterfase contribuyendo al desarrollo y fortalecimiento de la capacidad competitiva de las empresas mediante la realización de acciones del tipo:

1. Fomento y desarrollo de investigación cooperativa entre empresas, mediante programas de trabajo de interés común, de cuyos resultados pueden beneficiarse todas las empresas asociadas.

2. Colaboración en la transferencia de resultados de investigación entre los centros públicos de investigación y las empresas.

3. Prestación de asistencia y servicios tecnológicos, tales como calidad, formación, documentación, medioambiente, etc.

4. Desarrollo de proyectos de investigación y desarrollo tecnológico, para mejorar la competitividad de las empresas.

Por otra parte, la Universidad adquiere con el ITC un cauce de información privilegiada para orientar tanto su investigación como su formación académica hacia un sector de tanta relevancia en su entorno socio-económico.

En el aspecto tecnológico, el ITC vienen desarrollando las siguientes actividades: Proyectos de $\mathrm{I}+\mathrm{D}$, Asesoramiento Tecnológico, Transferencia de Tecnología y ciertos Servicios Tecnológicos (Análisis y ensayos, Laboratorio de producto acabado, Garantía de calidad, Información y documentación). Estas actividades, y concretamente las dirigidas al sector de fabricación de fritas, se realizan en las líneas de actuación siguientes:

- Desarrollo de productos (fritas, esmaltes y pigmentos) con características nuevas o mejoradas.

- Viabilidad de uso de nuevas materias primas así como residuos procedentes de otras industrias.

- Mejora de proceso y producto mediante la determinación de la influencia de las variables de producción.

- Diseño de sistemas para la mejora del proceso de fabricación, tanto desde el punto de vista técnico como de impacto medioambiental.

- Aplicación de energías renovables.

- Colaboración con ANFFECC en temas estratégicos para el sector.

Estas actividades se han plasmado a lo largo de los años en aportaciones al conocimiento del procesado de los materiales cerámicos reflejado en (periodo de 1991-2005) tales como 60 artículos, 34 proyectos de I+D propios, 149 proyectos de I+D financiado por empresas, 9 tesis doctorales y 7 patentes.

Concretamente, las tres empresas que más han contratado (11) son Esmalglass S.A., Fritta S.L. e ITACA S.A., que representan entorno al $60 \%$ de la contratación del ITC promedio. Es llamativo, no obstante, que otras cuatro grandes empresas del sector (Torrecid S.A., Colorobbia España S.A., Ferro Spain S.A. y Johnson Matthey Ceramics S.A.) apenas contratan en conjunto un $13 \%$ del total de lo contratado por el sector durante esos años con el ITC.

Como se precisa en el siguiente apartado, la contratación realizada por el ITC a través del departamento de Ingeniería Química (que para el ITC supone entorno al 50\% de su facturación), supone entorno al $70 \%$ del total contratado por la UJI con el sector de fritas. Estas cifras ponen de manifiesto que la principal entidad de investigación para el sector es el Instituto de Tecnología Cerámica (ITC). 


\section{5.- Las relaciones con las Universidades y Organismos} Públicos de Investigación.

El papel de la Universitat Jaume I de Castellón es notable por varios motivos. En primer lugar, su actividad formando técnicos para el sector, actividad fundamental para proveer del conocimiento básico en materiales y operaciones, que posteriormente repercute en la mejora de los procesos productivos, la calidad y en el desarrollo de nuevos productos. De nuevo aquí el papel del ITC a través del departamento de Ingeniería Química ha sido fundamental.

La actividad formativa se completa, en su fase de formación, con prácticas obligatorias tutorizadas en empresas (además de un practicum no obligatorio), para que las empresas se apoyen en equipos humanos altamente preparados. En el conjunto de la UJI, tres mil alumnos, que en algunas especialidades no llegan a cubrir la demanda de las empresas, realizan estas prácticas de carácter obligatorio, de entre doscientas cuarenta y trescientas sesenta horas de duración, dependiendo de la especialidad. Más concretamente, durante el curso 2005-2006 realizaron prácticas obligatorias en empresas treinta y cinco alumnos de la especialidad de Ingeniería Química, y sesenta y ocho de la Licenciatura en Químicas.

En segundo lugar, la investigación realizada en la UJI y dirigida al sector cerámico en su conjunto, se evidencia en las treinta tesis doctorales y veintiuna tesis de licenciatura publicadas entre 1994 y 2006 (11) (de las que dieciséis y nueve, respectivamente, corresponden al del departamento de Ingeniería Química vinculado al ITC); entre ésta se observa el predominio de la investigación sobre pigmentos, vidriados, fritas o esmaltes directamente vinculada al subsector de esmaltes, con dieciocho tesis doctorales y diez tesis de licenciatura. El esfuerzo en investigación se refleja, además, tras el análisis de las acciones (contratos de investigación, de asistencia, etc.) que han contratado las empresas de fritas y esmaltes con la UJI, principalmente a través del ITC, sin tener en cuenta las acciones de cooperación con otras empresas del entorno cerámico, para el periodo comprendido entre 1991 y 2004, ambos inclusive (ver Tabla XX).

TABLA XX: ACCIONES CONTRATADAS POR LAS EMPRESAS DE FRITAS CON LA UJI. 1991-2004.

\begin{tabular}{|l|c|c|c|c|}
\hline \multicolumn{1}{|c|}{ Tipo } & Importe & $\%$ & $\mathrm{~N}^{\circ}$ & Media \\
\hline Contrato de I+D & 4.198 .607 & 96,06 & 114 & $36.829,9$ \\
\hline $\begin{array}{l}\text { Contrato de Asesoramiento y } \\
\text { apoyo tecnológico }\end{array}$ & 35.460 & 0,81 & 5 & 7.092 \\
\hline Contrato de Asistencia Técnica & 33.681 & 0,77 & 103 & 327,0 \\
\hline Contrato de Formación & 103.132 & 2,36 & 2 & $51.566,0$ \\
\hline Total & 4.370 .879 & 100 & 224 & 19.513 \\
\hline
\end{tabular}

Fuente: Elaboración propia a partir de datos de la OCIT-UJI.

Concretamente, para este periodo se han contabilizado un total de doscientas veinticuatro acciones, con un gasto asociado de $4.370 .879 €$; principalmente con los tres departamentos técnicos (11) el Departamento de Ingeniería Química (integrado en ITC, por lo tanto que los datos mostrados en este apartado se refieren sólo a aquellos que el ITC contrata a través de su CIF de la UJI), el Departamento de Química Inorgánica y Orgánica y el Departamento de Tecnología. Entre las acciones, las más numerosas han sido los contratos de investigación, que han absorbido un 96'1\% de la contratación, con ciento catorce acciones. Tras estas destacan los ciento tres contratos de asistencia técnica, que han representado el $0^{\prime} 8 \%$ del total. Según expertos del sector, las empresas solicitan investigaciones muy aplicadas, dirigidas a la solución de problemáticas concretas. Esta tendencia parece haberse acentuado en los últimos años, como consecuencia de los menores márgenes de resultados. Por último cabe destacar dos contratos de formación, con un 2'4\% del importe económico. La Fig. 7. especifica el importe que ha contratado cada una de las empresas durante el periodo analizado, según el tipo de acción. En él se puede apreciar la diferente composición del gasto en acciones de cada una de las empresas.

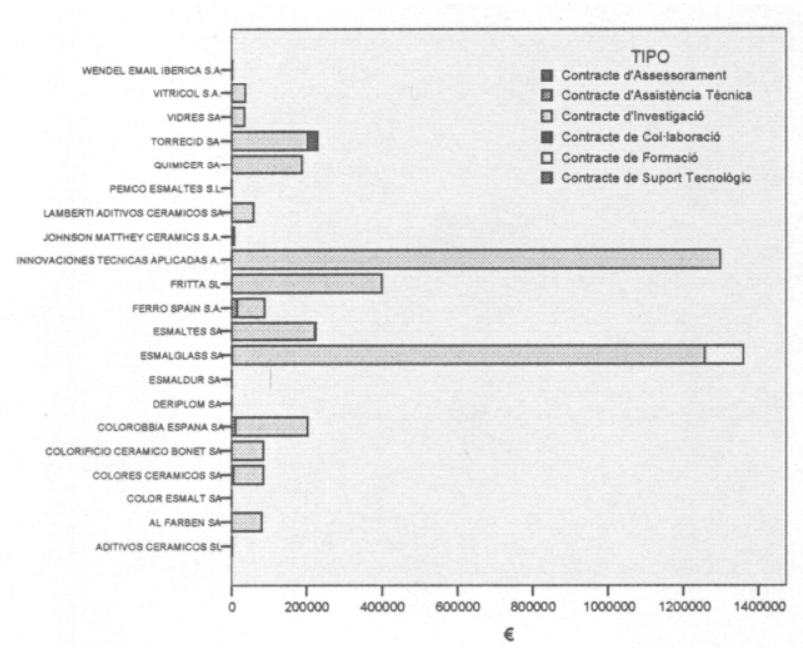

Fig. 7- Gasto en acciones por empresa y tipo de acción. 1991-2004. Industria de Fritas, Colores y Esmaltes Cerámicos. Fuente: Elaboración propia a partir de datos de la OCIT-UJI.

Por su parte, el instituto del CSIC que más ha trabajado con la industria cerámica y, particularmente, con las empresas de fritas, es el Instituto de Cerámica y Vidrio (ICV), con sede en Madrid y perteneciente al Área de Ciencia y Tecnología de Materiales del CSIC. Como se observa en la Tabla XXI, este instituto contrató con cuatro empresas de esmaltes por un valor total de un millón ciento treinta y seis mil euros. Entre estas se encuentran dos de las mayores empresas del sector, Torrecid y Ferro, y otra, Esmaltes S.A., que pese a su tamaño medio, ha realizado tradicionalmente esfuerzos significativos en I+D. Destaca la primera por contratar el $71 \%$ de todo lo contratado por las empresas del sector, y once veces más de lo que contrata con departamentos de la UJI. El ICV desarrolla sus actividades en el conjunto del sector cerámico y vidriero, por lo que las actividades relacionadas con el sector de pavimentos y esmaltes constituyen sólo una fracción menor de su actividad. Sus relaciones con el cluster de Castellón se efectúa en proyectos de mayor calado en investigación básica y más centrados en el medio plazo, como se deduce del mayor coste medio de los proyectos. Estos se han focalizado en el desarrollo de nuevos procesos, la apertura al campo de los nuevos materiales y estudios fisicoquímicos asociados a las propiedades de vidrios y esmaltes. Como actividad formativa, el ICV desarrolla desde hace 20 años un curso de especialización en materiales cerámicos y vítreos, destinado a titulados universitarios y dotado con 40 créditos, distribuidos entre las siguientes asignaturas: Relación Estructura-propiedades en materiales cerámicos, Diagramas de Equilibrio de Fases, Ciencia y Tecnología de Procesos en Cerámica y Vidrio; Los Vidrios: Fisico-química, 
Propiedades y Aplicaciones, Cerámica Estructural y Funcional, Materiales Refractarios, Electrocerámica, Comportamiento Termomecánico de Materiales Cerámicos y Vidrios, Análisis Químico de Materiales Cerámicos y Vidrios. Asimismo imparte dos asignaturas de doctorado ( Funadamentos Fisicoquímicos de los materiales cerámicos y vítreos (5 créd.) y Propiedades y Aplicaciones de .os Materiales Cerámicos y vítreos (5 cred.) dentro del programa La Química como Ciencia Multidisciplinar que imparte la Univerisdad Autónoma de Madrid y que posee la mención de Calidad del MEC.

TABLA XXI: ACCIONES CONTRATADAS CON EL INSTITUTO DE CERÁMICA Y VIDRIO. 1999-2004.

\begin{tabular}{|l|r|r|r|}
\hline \multicolumn{1}{|c|}{ Empresa } & \multicolumn{1}{|c|}{ Acciones } & Importe $(€)$ & \multicolumn{1}{c|}{$\%$} \\
\hline TORRECID, S.A. & 7 & 807.760 & 71,0 \\
\hline ESMALTES, S.A. & 1 & 228.393 & 20,1 \\
\hline FRITTA, S.L. & 2 & 58.898 & 5,2 \\
\hline $\begin{array}{l}\text { FERRO ENAMEL ESPAÑOLA, } \\
\text { S.A. }\end{array}$ & 3 & 41.879 & 3,7 \\
\hline Total & 13 & 1.136 .930 & 100 \\
\hline
\end{tabular}

Fuente. Elaboración propia a partir de datos de OTT-CSIC.

Por su parte, con el Instituto de Ciencia de los Materiales de Aragón contrataron dos empresas de esmaltes, si bien el montante contratado con este instituto está muy por debajo de lo contratado con el ICV. Así, Colorobbia S.A. contrató dos acciones por un total de sesenta y tres mil euros, y Esmaltes S.A. tuvo otros dos, de los que no se dispone la cifra. En conjunto, todas las acciones con ambos institutos del CSIC, diecisiete en total, fueron contratos de I+D.

\subsection{El capital humano. Factor de competitividad clave} para la industria.

En términos generales el distrito tiene abundancia de mano de obra con un nivel de formación suficiente(31); no obstante, se detectan insuficiencias en materia de formación de recursos humanos en áreas como gestión y dirección de empresas, diseño, marketing, logística, etc.

La Tabla XXII muestra las Ingenierías, Licenciaturas y cursos técnicos que imparten las Universidades y Escuelas de Arte de la Comunidad Valenciana. Tanto el primero como el último son cursos de ciento cincuenta horas especializados en pavimentos y revestimientos cerámicos, que imparte la Escuela Superior de Arte y Diseño en Castellón y en Valencia (Generalitat Valenciana). Son materias generales con nociones de química y diseño e incluyen cincuenta horas de prácticas en empresa. La diplomatura que imparte la Escuela Superior de Cerámica de Manises, Valencia, comprende tres cursos académicos ( 270 créditos), de forma que, a partir del segundo, se establecen dos itinerarios a elegir: Arte Cerámico o Ciencia y Tecnología. Las dos Ingenierías y la Licenciatura que imparte la Escuela Superior de Tecnología y Ciencias Experimentales de la UJI incluyen algunas materias optativas en los últimos cursos, relacionadas directamente con la industria cerámica, pero no existe una clara especialización.

Expertos entrevistados indicaron que las empresas de este sector no incluyen la formación en su plan estratégico, ni constituye uno de los ejes básicos del departamento de recursos humanos. Tampoco se puede hablar de la existencia de programas de formación, ni de programas de detección de necesidades de formación, sino más bien de cursos aislados que se dirigen al personal de administración y al departamento
TABLA XXII. INGENIERÍAS, LICENCIATURAS Y CURSOS TÉCNICOS RELACIONADOS CON LA CERÁMICA OUE SE IMPARTEN EN LA COMUNIDAD VALENCIANA. 2004.

\begin{tabular}{|c|c|c|}
\hline CENTRO & CURSO / TITULACION & AREA \\
\hline $\begin{array}{l}\text { Universitat Jaume I de } \\
\text { Castellón: ESTCE }\end{array}$ & $\begin{array}{l}\text { - Ingeniería Química } \\
\text { - Ingeniería Técnica en Diseño } \\
\text { Industrial } \\
\text { - Licenciatura en Química }\end{array}$ & $\begin{array}{l}\text {-Química } \\
\text {-Diseño general } \\
\text {-Química }\end{array}$ \\
\hline $\begin{array}{l}\text { Escola d'art superior de } \\
\text { disseny (Castellón) }\end{array}$ & $\begin{array}{l}\text { Ciclo formativo de grado } \\
\text { superior en Pavts. y Revest. } \\
\text { Cerámicos }\end{array}$ & $\begin{array}{l}\text { - Diseño de } \\
\text { pavimentos }\end{array}$ \\
\hline \multirow{2}{*}{$\begin{array}{l}\text { Escuela Superior de } \\
\text { Cerámica (Valencia) }\end{array}$} & $\begin{array}{l}\text {-Diplomatura: Estudios } \\
\text { Superiores de Cerámica }\end{array}$ & $\begin{array}{l}\text {-Cerámica } \\
\text { general }\end{array}$ \\
\hline & $\begin{array}{l}\text {-Curso: Técnico Superior en } \\
\text { Pavts. y Revest.Cerámicos }\end{array}$ & $\begin{array}{l}\text {-Diseño de } \\
\text { pavimentos }\end{array}$ \\
\hline
\end{tabular}

Fuente: Elaboración propia.

de diseño para responder a necesidades concretas y puntuales, siendo prácticamente nulas las acciones formativas dirigidas al resto de trabajadores (mantenimiento, serigrafía, pintado a mano, esmaltadora y hornos).

Concretamente, las empresas utilizan las modalidades de formación continua y formación reglada (acogen a estudiantes en prácticas de F.P. y universidad en los departamentos de administración, diseño y laboratorio). La formación reglada se imparte en el Instituto de Formación Profesional N ${ }^{\circ}$ II, el Instituto de Formación Profesional de Onda/Alcora, la Escuela Superior de Cerámica de Alcora, La Escuela de Artes Aplicadas y Oficios Artísticos y la Universitat Jaume I de Castellón (un $65 \%$ de la docencia en la titulación de Ingeniero Químico es impartida por profesores del Departamento de Ingeniería Química integrados en la plantilla del ITC). La formación continua se ofrece a través de las instituciones soporte y asociaciones mencionadas anteriormente, especialmente el curso para técnicos y diseñadores del ITC-ALICER, y cursos para directivos en ASCER.

Además proliferan en este sector múltiples y variados cursos a cargo de organismos oficiales, centros formativos o empresas privadas (Cámara Oficial de Comercio, Industria y Navegación, Confederación de Empresarios de Castellón, Instituto de Tecnología Cerámica o consultoras privadas, fundamentalmente en aspectos químicos, idiomas o informática) y en algunos de ellos están empezando a participar trabajadores del sector. Las acciones formativas se llevan a cabo fuera de la empresa y van dirigidas principalmente al personal joven de la empresa, que está más interesado.

Además, hay que resaltar que se dedica un mínimo porcentaje del total de facturación a la formación y tampoco se destinan suficientes recursos humanos a ello; todavía subsiste la concepción de que es un gasto más que una inversión.

Las empresas están empezando a sensibilizarse respecto a la importancia y posibilidades de la formación en un ámbito organizacional caracterizado por las constantes innovaciones tecnológicas. Es fundamentalmente en relación a la entrada de innovación tecnológica, donde se percibe la formación como más necesaria, porque la incorporación de nueva tecnología supone un cambio en el nivel de cualificación de los usuarios de dicha tecnología y requiere que éstos sean formados convenientemente para su manejo.

El ITC considera prioritaria la formación tanto de técnicos 
del sector como de su propio equipo de investigadores. A fin de difundir los conocimientos adquiridos a través de la actividad de la investigación, el ITC organiza actividades formativas dirigidas a personas con responsabilidad técnica en las empresas. Por su parte, la ATC se preocupa por la formación de sus asociados y organiza diversas "jornadas técnicas" en colaboración con otras entidades, sobre temas variados.

5.7. Contribuciones del subsector de esmaltes al sistema de innovación de la industria cerámica.

La evolución tecnológica ha sido muy intensa. La tecnología en los esmaltes ha pasado de ir inicialmente de la mano de los artistas ceramistas y pequeños artesanos e industriales, integrada en las propias industrias, a ser una actividad dominada por el conocimiento científico, con químicos e ingenieros en el primer plano.

El conocimiento en el campo de los pigmentos fue desarrollado por las grandes empresas internacionales, como BASF, BAYER, Ferro o Degussa, a partir de los años cuarenta. Se partió de un modo muy empírico, con relativa poca base científica y de un modo interno, cerrado, a aquellas grandes empresas. Con el desarrollo de la industria cerámica y la externalización de los esmaltes, se comienza a requerirse la presencia de titulados especializados. Estos procedían, primero, de la Universidad de Valencia y luego, desde el ITC y la UJI de Castellón. Su incorporación supuso un revulsivo para esta industria que pudo, no sólo mejorar los procesos productivos del esmalte, sino además incrementar el valor añadido de su producto por medio de ofrecer apoyo técnico y diseño a sus clientes de la industria cerámica.

Se puede determinar dos grandes periodos, grosso modo, en función del origen de la innovación. Un primer periodo, comprendido entre los años cuarenta hasta principios de los ochenta, dónde se produjeron las principales innovaciones de proceso (en prensas, hornos, etc.) cuyo origen es principalmente italiano. Y un segundo periodo, desde los años ochenta, dónde si bien los fabricantes de bienes y equipos han seguido aportando innovaciones, las mayores contribuciones han sido innovaciones de producto que han venido de la industria de esmaltes, o de innovaciones de proceso surgidas de la colaboración de éstas con empresas de bienes de equipo.

De modo sintético, se describen someramente los grandes hitos acaecidos en el proceso, vinculados al sector de esmaltes:

- Sustitución o reducción de componentes cuestionados tales como el plomo, el selenio o el antimonio en los esmaltes, tarea conseguida a partir de 1975, por derivados de zirconio y óxido de zinc, que supusieron mejoras en la salud laboral.

- Desarrollo de la tecnología de la monococción porosa para la fabricación del azulejo. Es sin duda una de las mayores aportaciones ya que supuso grandes reducciones de costes (energéticos y de tiempo), simplificación del proceso, mejores calidades obtenidas, nuevos esmaltes de apoyo y unos nuevos servicios a los clientes.

- Desarrollo de la atomización, técnica que permite una mayor compactación, que surgió vinculada al desarrollo de la monococción. La temperatura de trabajo necesaria para la atomización (entorno a los $500 \mathrm{C}^{\circ}$ ) estimuló así mismo la implementación de la cogeneración para reutilizar los excedentes térmicos en otros procesos

- Desarrollo de esmaltes nuevos: microgránulos, atomizados, escamas, granillas, metalizados, sanitarios, etc. y adquisición de los equipos necesarios para su fabricación.

- Desarrollo de esmaltes para el gres porcelánico que permiten lograr un producto de gran calidad y más diferenciado que el porcelánico técnico, con menores costes.

- Desarrollo de tecnologías de decoración para el esmaltado de las baldosas: por contacto (rodillos, serigrafía (plana y rotativa)) y por inyección digital de tinta en cooperando con los fabricantes de maquinaria para el diseño de nuevas instalaciones y equipos que luego difunden entre los ceramistas.

La estrategia de las empresas de fritas se orienta a apoyar a sus clientes en su lucha competitiva en dos sentidos. En primer lugar, con una actividad de innovación dirigida a mejorar calidad en las materias primas del esmaltado, sus prestaciones, estética y diseño, lo que redunda en una mayor diferenciación para los productos cerámicos. En segundo lugar, con un completísimo servicio al cliente que incluye no solo los servicios previos a la elaboración del producto, como el diseño, sino además los posteriores a la venta, prestándole su máximo apoyo en la puesta a punto y solución de todos aquellos problemas que pudiesen surgir en la fase de producción.

En efecto, la industria ha tenido y tiene un activo papel en el proceso de generación de nuevo conocimiento y en su aplicación y desarrollo, en los que la cooperación con otras empresas y sectores componentes de sector cerámico no está ausente (22). Así las empresas de fritas han construido plantas piloto para servicio de los fabricantes de maquinaria al objeto de, en condiciones semiindustriales, diseñar la fabricación de los nuevos productos con los nuevos esmaltes, cooperando, también, con los clientes finales, en la valoración de los costes de inversión y de fabricación futuros. Además contratan y forman a los recursos humanos que llevaran a cabo la fabricación definitiva, mejorando previamente los prototipos de máquinas y esmaltes en colaboración estrecha con los clientes finales y los proveedores de maquinaria, realizando proyectos conjuntos a tres bandas.

No obstante, se puede decir que nos encontramos en un momento de inflexión en lo que a la dirección y ámbito de las innovaciones se refiere. Si desde el desarrollo de la monococción porosa, a mediados de los años ochenta, el mayor esfuerzo en innovación en España vino de la mano de los técnicos químicos, veinte años después, la parte química del proceso han alcanzado un nivel de desarrollo difícil de superar, y las mejoras, quitando las relacionadas con la reformulación de productos sustituyendo o reduciendo materias primas encarecidas, tienden a orientarse hacia las fases de diseño, como el desarrollo de la decoración digital inkjet.

Se apuntan, pues, tres grandes líneas de investigación prometedoras en el sentido de que permiten dar respuesta a la nueva competencia asiática en el contexto globalizador actual:

1. La búsqueda de otros elementos opacificantes que sustituyan al zirconio y al óxido de zinc dado su elevado coste.

2. El desarrollo de la decoración digital por inyección de tinta (sistema inkjet), aplicada a las baldosas cerámicas. El sistema formado por tinta de colores adaptada, los inyectores y el software de control gráfico viene a revolucionar la decoración en cerámica porque introduce una gran versatilidad y celeridad en el cambio de modelo, permitiendo una personalización de diseños, con series cortas.

3. La investigación en cerámicas "funcionales". Se persigue elaborar esmaltes capaces de desarrollar funciones específicas 
en la cerámica: a) sistemas de captación de energía (cerámicas fotovoltaicas y solares); b) aplicaciones higiénicas (cerámicas bactericidas); c) conducción eléctrica (esmaltes conductores); d) para aplicaciones domóticas; e) para competir con el parquet (esmaltes no fríos al tacto), etc.

Es previsible que de la nanotecnología provengan en el futuro próximo grandes aplicaciones de utilidad para este subsector. Además, temas como la adaptación a normativas medioambientales, el ahorro energético, igualmente seguirán siendo orientadores en el campo de la investigación y desarrollo.

\section{CONCLUSIONES}

La industria de Fritas, Esmaltes y Colores cerámicos viene ejerciendo una intensa actividad de innovación, generando y transfiriendo tecnología a las empresas cerámicas, tanto de manera individual como en colaboración con las empresas de maquinaria. En los mercados ha efectuado un esfuerzo de internacionalización, tanto en su vertiente estrictamente comercial, vendiendo en el exterior hasta $60 \%$ de su producción, como instalando en numerosos países nuevas plantas de fabricación para suministrar a los fabricantes de cerámica locales, practicando un liderazgo reconocido por todos. Liderazgo basado en: a) La formación y cualificación de su personal. Desde principio de los 70, la incorporación de químicos e ingenieros químicos ha sido incesante, elevando considerablemente la capacidad de generación y de absorción de nuevo conocimiento. b) La calidad alcanzada por sus productos y por los servicios de valor añadido. Se ha mejorado la calidad técnica y estética de los productos que se han aplicado también por ampliación del mercado, pasando del azulejo (paredes) al pavimento (suelo) y a otras aplicaciones cerámicas (fachadas, etc.). La industria del esmalte ha contribuido al éxito del sector de baldosas y recubrimientos cerámicos de Castellón. c) La contribución a la innovación continúa en las nuevas y mejores tecnologías de fabricación entre los ceramistas, supliendo, en cierto modo, el déficit presencial del subsector mecánico. Así, ha sucedido con los hornos de cocción y en otras fases del proceso de fabricación, reduciendo el número de cocciones y consumos energéticos. Y d) La internacionalización y multilocalización. Con una estrategia clara de crecimiento y aproximación a la industria cerámica a nivel global, en los planos comercial, de asistencia técnica y de fabricación, el subsector tiene filiales en más de veinte países distintos. Italia, Brasil, México, Indonesia, Portugal, China y otros países de Europa centran los esfuerzos de internacionalización.

La innovación en el sector cerámico estuvo impulsada por las empresas de bienes de equipo hasta los años 80. A partir de entonces, las fritas han contribuido decisivamente en las innovaciones de este sector, tanto en las innovaciones de proceso, caso de la monococción porosa o más recientemente la inyección digital de tinta, como en las innovaciones de producto basadas en nuevos esmaltes y diseños.

Las actividades de innovación han decrecido en los últimos años por lo que la intensidad de innovación del subsector es menor actualmente que la media de la industria valenciana. La innovación la llevan a cabo las empresas principalmente de forma individual, con sus propias capacidades. La cooperación entre las empresas del subsector para innovar es prácticamente inexistente porque su grado de competitividad depende directamente de estas innovaciones, pero tampoco se produce una cooperación elevada en actividades de I+D con la UJI o con el ITC o el ICV. El papel de estas instituciones proviene esencialmente de su capacidad formadora de personal cualificado. La mayor cooperación se produce con las empresas de bienes de equipo.

El horizonte próximo para la industria de fritas, colores y esmaltes cerámicos, se ve nublado por ciertos problemas relevantes que pueden limitar su futura capacidad financiera para seguir invirtiendo en innovación. Por tanto, son problemas a los que tiene que enfrentarse. A saber:

- Pérdida de rentabilidad: La estructura de la industria ha reflejado la presencia de una competitividad interna basada, por un lado, en la presión de los clientes y también, por la entrada constante de nuevas empresas en el mercado y por el aumento de precios de ciertas materias primas, lo que ha significado una mejora de la calidad de productos y servicios, pero que no se ha correspondido con aumentos de los precios reales sino, más bien al contrario, con una reducción de los mismos. Ello se ha traducido en una intensa pérdida de rentabilidad contrastada en este trabajo, especialmente pronunciada desde el 2001, momento a partir del cual se ha producido una escalada de los precios de las materias primas y del gas natural, constituyentes del $75 \%$ de los costes de producción.

- Presión competidora en el mercado mundial: Con el proceso expansivo de la ind ustria asiática del esmalte, iniciados los procesos de liberalización desde 2005, se avistan problemas de exportación a mercados lejanos para las industrias española e italiana, que trabajan con costes más altos y que afrontan inversiones impuestas por regulaciones medioambientales que los competidores no llegan a asumir. Sólo la calidad del producto y del servicio añadido permitirá el mantenimiento del liderazgo.

- Problemas regulatorios: Con una gran adaptabilidad ante los cambios, la industria de esmaltes está sabiendo dar respuesta a los retos que plantea una legislación medioambiental cada vez más rigurosa en el seno de la Unión Europea. Por un lado, el sector manifiesta haber venido aplicando, desde hace años, las mejores tecnologías disponibles (BATs) para el control y minimización de emisiones y residuos contaminantes, potencialmente peligrosos, cooperando con los organismos públicos en temas de seguridad y desarrollo sostenible. Esta actitud, parece haber tenido resultados positivos en al menos dos aspectos: uno, en lo que respecta a la implantación de lo previsto en el documento BREF sectorial y en la consecución de la Autorización Ambiental Integrada y también, en lo que respecta a la regulación REACH relativa a productos químicos peligrosos; aquí, se interviene en perfilar su aplicación de forma que, cumpliendo los objetivos perseguidos por la ley, no llegue a implicar excesivas inversiones adicionales en seguridad. Finalmente, otra implicación, no abordada extensamente en este trabajo, se refiere al reto de las emisiones de gases con efecto invernadero, por la adhesión de España al Protocolo de Kyoto. La asignación de emisiones de CO2 a la industria para los próximos años, apenas permite aumentar la producción en territorio español, por lo que de no revisarse al alza, dado el previsiblemente alto coste de adquisición de derechos de emisión (que se sumaría a los demás ya mencionados), abocaría a estudiar y posiblemente a adoptar estrategias más intensas de deslocalización.

Soluciones a la problemática reflejada cabe encontrarlas en la adopción de estrategias ya conocidas y acometidas, aunque 
con enfoques novedosos:

- Reorganización industrial: Fusiones y adquisiciones, y especialización.

- Internacionalización: búsqueda de nuevos clientes y la multilocalización.

- Potenciación de la innovación en colaboración con otros actores del sistema de innovación para encontrar aquellos avances tecnológicos que consigan mantener el liderazgo del subsector. En este sentido, se han apuntado tres grandes líneas prometedoras que permiten dar respuesta a la nueva competencia asiática en el contexto globalizador actual.

En definitiva, el subsector se encuentra en una encrucijada en la que tiene dificultades para encontrar la dirección a tomar. El optimismo de antaño se ha ido transformando en un peligroso pesimismo según ha ido disminuyendo la rentabilidad. El subsector $y$, en general, el sistema de innovación cerámico necesitan elaborar una agenda en la que se fijen unos pocos retos importantes cuyo logro se considere imprescindible para mantener el liderazgo del distrito cerámico. Esta agenda debe ser elaborada conjuntamente por los distintos actores del sistema de innovación y la resolución de los grandes retos debe buscarse mediante la cooperación de los mismos. La globalidad implica nuevos comportamientos y uno de los más importantes es el aumento de la cooperación entre los actores del sistema de innovación.

\section{AGRADECIMIENTOS}

Los autores agradecen al Alto Consejo Consultivo de la Generalitat Valenciana la financiación para realizar esta investigación, y a las siguientes personas y entidades por su inestimable ayuda y amabilidad: Estefanía Aguilar Moreno, documentalista del ITC. Jorge Bakali Bakali, presidente de la Sociedad Española de Cerámica y Vidrio. José María Batán, presidente de la ATC. $\mathrm{M}^{\mathrm{a}}$ Isabel Beas Collado, del Área de Inserción Profesional, OCIE, UJI. Juan B. Carda, profesor del Departamento Química Inorgánica y Orgánica. UJI. José A. Cerisuelo Bellmunt, director técnico de ZIRCONIO S.A., Francisco Corma Canós, consultor y asesor de empresas. Emilio Criado, investigador del Instituto de Cerámica y Vidrio (CSIC). Daniel Chornet Beltrán, Jefe del Servicio de Estadísticas Económicas, del IVE. Enrique Dominguez Agut, jefe del Área de Estudios Económicos. COCIN de Castellón. Guillermo Peris Fajarnes, profesor del Departamento de Tecnologías Gráficas, de la UPV. Carlos Felíu Mingarro, director del ITC. Juan José Gargalló Escribá, responsable del departamento de calidad de ZIRCONIO S.A. Carlos Gonzalvo Lucas, director general de Vernís y expresidente de ANFFECC. Begoña Jáuregui Ríos, jefa de Área Técnica, del IVE. Fernando Lucas Martín, director técnico de Fritta. Francisco Javier Molina Morales, profesor del Departamento de Administración de Empresas y Marketing UJI. Arnaldo Moreno Berto, seecretario del ITC. José Ribera Facundo, expresidente de la ATC. Ismael Rodrigo, director OCIT de la UJI. Rafael Vicent Abella, director técnico de Kerajet.

\section{BIBLIOGRAFÍA}

1. K. Pavitt, Sectoral patterns of technical change, Res. Policy, 13, 6, 343-373 (1984)

2. G. Becattini, Del distrito industrial marshalliano a la teoría del distrito contemporánea. Una breve reconstrucción crítica, Investig. reg., 1, 9-32 (2002)

3. A. Escardino, La innovación tecnológica en la industria cerámica de
Castellón, Bol. Soc. Esp. Ceram. V., 40 ,1, 43-51 (2001)

4. G. López, Fritas, esmaltes y colores. Competencia interna y expansión exterior, Constr. Alimarket. Informe Materiales, 44-49 (2003)

5. S. Gil, R. Llorca, El sector de las baldosas de cerámica en España. Distrito industrial y competitividad, Econ. ind., 355/356, 229-238 (2004)

6. D. Nager, G.P. Crasta, Glaze and colour companies face soaring costs, Ceram. World Rev., 67, 70-77 (2006)

7. I. Fernández, D. Gabaldón, C. Gómez, La innovación en el sector de pavimentos y revestimientos cerámicos de la Comunidad Valenciana, Alto Consejo Consultivo en I+D de la Presidencia de la Generalitat Valenciana. Valencia (2005)

8. J. Albors, X. Molina, La difusión de la innovación, factor competitivo en redes interorganizativas: el caso de la cerámica valenciana, Econ. ind., 339, 167-175 (2001)

9. Anónimo. Las fábricas de esmaltes, un eslabón esencial. Una aproximación a la importancia estratégica de los fabricantes españoles de esmaltes, Guía de empresas y productos. Técnica cerámica. 2005-06, 14-19 (2006)

10. J. Albors, J. L. Hervás, La industria cerámica europea en el siglo XXI. Retos tecnológicos y desafíos de próxima década, Bol. Soc. Esp. Ceram. V., 45, 1, 13-21 (2006)

11. D. Gabaldón, E. Tortajada, I. Fernández, El papel de las fritas, colores y esmaltes en la evolución del sector cerámico de la Comunidad Valenciana, Presidencia de la Generalitat Valenciana, Fundación Premios Rey Don Jaime I, Valencia (2008) (en prensa)

12. M. Illueca, L. Martínez, Crecimiento y productividad en el sector español de fritas, esmaltes y colores cerámicos, Rev. valencia. econ. Hacienda, 4- I, 129-152 (2002)

13. L. Martínez, Evolución de la rentabilidad económica y financiera del sector de Fritas, Esmaltes y Colores Cerámicos, Universitat Jaume I, Castellón (2002)

14. A. M. Fuertes, (Dir.). El distrito industrial de la Cerámica. Claves de la competitividad de la economía de Castelló, Fundación Dávalos-Fletcher, Castellón (2005)

15. C. Gonzalvo, M. Irún, La fabricación de fritas, esmaltes y colores cerámicos. Retos sociales, económicos y medioambientales en el contexto internacional, Qualicer'06. 3-23 Castellón (2006)

16. ASCER, Los sectores español y mundial de baldosas cerámicas. Informe 2004. Asociación Española de Fabricantes de Azulejos y Pavimentos Cerámicos, Castellón (2004)

17. J. R. Hernández, Análisis espacio-temporal de la evolución de la producción cerámica azulejera valenciana. Una ilustración del proceso de reubicación intraregional de los distritos industriales cerámicos valencianos. 153-162. A. Fuster, J.M. Giner, M.J. Santa María (eds.), La economía regional ante la globalización, Universidad de Alicante, San Vicente del Raspeig (2006)

18. E. Criado, E. Sánchez, M. Regueiro, La industria cerámica española, ¿ante un cambio de ciclo?, Bol. Soc. Esp. Ceram. V., 43, 1, 85-101 (2004)

19. T. Bursi, S. Franzoni, Colorificio Ceramici: profilo di settore e strategie di internazionalizzazione. T. Bursi, G. Marchi, G. Nardin, Il Sistema ceramico di fronte alla globalizzazione: strategie di impresa e strategie di sistema, Università degli studi di Módena e Regio Emilia, Departamento di Economia Azindale, Módena (2006)

20. Ceram. World Rev., 50-56 (2003-2004)

21. F. G. Richidiardiello, D. Minichelli, Tendencias y problemas de la industria cerámica italiana. Qualicer'06, 77-85 (2006)

22. P. Baigorri, La industria española de esmaltes: la nueva revolución, Téc cerám., 326, 908-18 (2004)

23. E. Criado, Reflexiones sobre el futuro de la Industria Europea de la Cerámica, Bol. Soc. Esp. Ceram. V., 46, 39-46 (2007)

24. A. González, Entrevista en: La Cámara de Comercio de Castellón informa, $169,10-11(2007)$

25. Ministerio de Medio Ambiente. Documento de Orientación Sectorial para la medición, cálculo y estimación de emisiones de sustancias EPER (Inventario Europeo de Emisiones y Fuentes contaminantes), Sector del Vidrio, Julio de 2003 (2003)

26. I. Fernández, F. Conesa, (coords.) Estructuras de interfaz en el sistema español de innovación: su papel en la difusión de tecnología, Universidad de Politécnica de Valencia. Valencia (1996)

27. I. Fernández, A. Gutiérrez, F. Jiménez, J. M. Azagra, Las debilidades y fortalezas del Sistema Valenciano de Innovación. 251-278. M. Olazarán y M. Gómez (eds.) Sistemas Regionales de Innovación, Universidad del País Vasco, Bilbao (1999)

28. Fundación Bancaja. El Cluster cerámico en Castellón: iniciativa de refuerzo de la competitividad, Bancaja, Valencia (1999)

29. A. Barba, From Chemical Engineering to Ceramic Technology: A Review of Research at the Instituto de Tecnología Cerámica, Bol. Soc. Esp. Ceram. V., $44,3,155-168$ (2005)

30. INE. Encuesta sobre innovación tecnológica en las empresas 2004. Instituto Nacional de Estadística, Madrid (2006)

31. J. J. Juste La industria cerámica: el sistema productivo local de Castellón, An. estud. econ. empres., 11, 491-509 (1996)

Recibido: 28.03 .08

Aceptado: 31.03 .08 